Article

\title{
How Credible Are Shrinking Wage Elasticities of Married Women Labour Supply?
}

\author{
Duo Qin *, Sophie van Huellen and Qing-Chao Wang \\ Received: 12 October 2015; Accepted: 10 December 2015; Published: 25 December 2015 \\ Academic Editor: Kerry Patterson \\ Department of Economics, School of Oriental and African Studies (SOAS), University of London, \\ Thornhaugh Street, Russell Square, London WC1H 0XG, UK; sv8@soas.ac.uk (S.V.H.); \\ qw2@soas.ac.uk (Q.-C.W.) \\ * Correspondence: dq1@soas.ac.uk; Tel.: +44-0-207-898-4624
}

\begin{abstract}
This paper delves into the well-known phenomenon of shrinking wage elasticities for married women in the US over recent decades. The results of a novel model experimental approach via sample data ordering unveil considerable heterogeneity across different wage groups. Yet, surprisingly constant wage elasticity estimates are maintained within certain wage groups over time. In addition to those constant wage elasticity estimates, we find that the composition of working women into different wage groups has changed considerably, resulting in shrinking wage elasticity estimates at the aggregate level. These findings would be impossible to obtain had we not dismantled and discarded the instrumental variable estimation route.
\end{abstract}

Keywords: labour supply wage elasticity; instrumental variable; selection bias; parameter stability

JEL classification: J22; C18; C52; C55

\section{Introduction}

Shrinking wage elasticities for married women in the US over the past decades have become almost a stylized fact [1], challenging the historically ${ }^{1}$ established gap between male and female wage elasticities. For instance, Blau and Kahn [5] find a steady and dramatic reduction in women's wage elasticity by about 50 to 56 per cent during the 1980-2000 period, with respect to both labour force participation and hours of work. Likewise, Heim [6] observes a 60 to 95 per cent reduction in intensive and extensive margins from 1979 to 2003. Theoretically, these developments are linked to disbanding traditional gender roles [7] and increasing wage opportunities for women [8].

Empirical studies on the wage elasticity gap between males and females are predominantly executed at the micro level. However, microeconomic elasticity estimates vary greatly across studies $[9,10]$ and microeconomic estimates of labour supply elasticities based on hours of work tend to be smaller than elasticities implied by macroeconomic models [11]. ${ }^{2}$ The variety of estimates presented by micro models alone as well as the unresolved discrepancy between macro and micro

1 Historically women's wage elasticity is found to be considerably higher relative to their male counterparts [2,3]. The theoretical premise for this is that the income effect for women is small while the substitution effect dominates. This is explained by the traditional division of labour within families where wives are assumed to substitute between household tasks, market work, and leisure while men only substitute between the latter two. Since household tasks and market work are close substitutes, the wage substitution effect is arguably large for women, which results in a positive uncompensated wage effect (income and substitution effect) and relative elastic female labour supply with respect to wage rate, e.g., [4].

2 Although studies suggest taking the microeconomic estimate for calibrating aggregated macroeconomic models [12], such practice has been heavily criticised $[13,14]$ and no consensus has been found yet. 
results call for a thorough assessment of the consistency of wage elasticity estimates. This study contributes to a better understanding of these anomalies in two important ways. Firstly, the instrumental variables (IV) method based on which the shrinking elasticities are obtained is critically assessed. Secondly, a novel approach based on data ordering techniques is proposed, which yields more consistent and robust wage elasticity estimates with surprising implications for the common finding of shrinking wage elasticities.

Shortcomings of the IV method are widely acknowledged in the existing literature. Despite the wide acknowledgement, these shortcomings are frequently glossed over in applied studies [15] or parametric approaches are rejected altogether; see [16] for a literature survey. Following recent insight on the IV route provided by Qin [17,18], this paper argues that the IV treatment to key variables of interest is even more costly than commonly acknowledged. Taking the labour supply model for married women as a case study, the costs are clearly illustrated by comparison of IV estimates with results obtained through the novel model experiment based on data ordering techniques. This novel parametric approach is not only close to the economic interpretation of wage elasticities, but also yields additional insights into the nature of wage elasticities within various samples of married working women.

In particular, it is shown that wage elasticity parameters vary substantially across different wage groups and even turn negative for high wage earners. By sample ordering we are able to locate a wage range within which wage elasticity parameters are constant, positive and highly significant. We show that this wage range and parameter estimates are surprisingly invariant across different waves, while the share of women in this wage range falls over time. These findings shed new light on the phenomenon of shrinking elasticities for married women in the US. Against the background of the results obtained through sample data ordering, we argue that the finding of shrinking elasticities is actually a result not of changes in disaggregate elasticities per se, but a shifting composition of working women in different wage segments over the last decades. Further, the discovery of significant heterogeneity among working women puts into question the assumption of single valued elasticities using micro data and calls for a theoretical reorientation for those aiming to align micro with macro estimates.

The microeconomic female labour supply model is commonly estimated taking married women at their prime working age with working husbands as the target group. We will follow this approach taking two widely used US based cross-section data sources into consideration-the Current Population Survey (CPS) and the Panel Study of Income Dynamics (PSID). The parallel use of the CPS and PSID sources provide us with a powerful means of cross-checking the degrees of inferability between samples. Wage elasticities are estimated for the years 1980, 1990, 1999, 2003, 2007, and 2011. Firstly, these years coincide with the time periods investigated by two core papers, $[5,6]$, which are based on CPS data, and hence make a good comparative case. ${ }^{3}$ Secondly, the selected years go beyond the time frame previously analysed. A detailed description of the datasets and the processing of the data can be found in Appendix A.1.

The remainder of the paper proceeds as follow. Section 2 assesses the empirical consistency of IV based wage elasticity estimation. Section 3 suggests alternatives towards a more robust and consistent wage elasticity estimate. Section 4 concludes and provides an outlook for future research.

\section{How Consistent Are Endogeneity-Bias Treated Elasticity Estimates?}

Let us start from the following cross-section data based empirical model of labour supply for married women in accordance with [5,6]:

3 Blau and Kahn [5] pool 1979-1981, 1989-1991 and 1999-2001 into three samples. We simply choose one mid wave for each of the three. However, we choose 1999 for the third wave because the PSID source does not provide 2000 data. 


$$
H_{i}=\alpha_{0}+\alpha_{1} \ln \left(w_{i}\right)+\alpha_{2} \ln \left(I_{i}\right)+\sum_{j} \beta_{j} X_{i j}+\varepsilon_{i}
$$

where $H_{i}$ denotes wife's total hours of work in household $i, w_{i}$ her wage rate, $I_{i}$ her husband's wage rate or income, and $\left\{X_{i j}\right\}$ a set of explanatory variables of demographic characteristics, such as wife's age, education, work experience and the number of children in the household; $\alpha_{1}$ and $\alpha_{2}$ are wage elasticity and hours income elasticity respectively. Here, our focal interest is $\alpha_{1}$.

It is almost standard practice ${ }^{4}$ to estimate model (1) via an IV treatment to $w_{i}$ due to assumed presence of endogeneity bias-i.e., bias which is caused by either simultaneity between $H_{i}$ and $w_{i}$, or self-selection or omitting correlated variables, or any combination of the three according to textbooks. The IV treatment amounts to re-specifying (1) into a two-equation model:

$$
\begin{aligned}
& \left.H_{i}=\alpha_{0}+\alpha_{1} \widehat{\ln \left(w_{i}\right)}\right)_{I V}+\alpha_{2} \ln \left(I_{i}\right)+\sum_{j} \beta_{j} X_{i j}+\varepsilon_{i} \\
& \ln \left(w_{i}\right)=\lambda_{0}+\sum_{k} \lambda_{k} Z_{i k}+u_{i} \Rightarrow \widehat{\ln \left(w_{i}\right)_{I V}}
\end{aligned}
$$

which underlies the two stage least square (2SLS) estimation procedure of IV models. In (2), $\left\{Z_{i k}\right\}$ is a set of IVs. When selection bias is of concern, an inverse Mills ratio, $\rho$, is commonly included in $Z$. The ratio is derived from the residual density function of the following binary response model of labour force participation:

$$
\begin{gathered}
P_{i}=\theta_{0}+\theta_{1} \ln \left(I_{i}\right)+\sum_{m} \kappa_{m} Y_{i m}+\epsilon_{i} \quad P_{i}= \begin{cases}1 & \text { if } w_{i}>0 \\
0 & \text { if } w_{i}=0\end{cases} \\
\rho=\frac{\phi\left(\epsilon_{i}\right)}{\Phi\left(\epsilon_{i}\right)}
\end{gathered}
$$

where $\{\ln (I), Y\} \supsetneq Z$. Probit is normally used to estimate (3) according to the Heckman two-step procedure [22].

Let us now ponder over the plausible causes of endogeneity bias here. First of all, there lacks economic ground to assume that married women in general should have the wage bargaining power through their choice of working hour supply. Even if assuming a certain bargaining power this probably arises from seniority, status at the workplace and union representation rather than hours worked [23]. Hence, simultaneity cannot be a serious concern. As for the risk of omitting correlated variables, the best strategy is to include them directly into (1) as control variables. The only plausible concern is selection bias. Here it should be noted that the Heckman procedure only treats possible self-selection bias, rather than possible sampling selection bias resulting from the truncated nature of $H_{i}$, since the IV correction in (2) does not cover $\alpha_{2}$ or $\beta_{i j}$.

While the worry over endogeneity bias is economically unfounded in the case of working wives' wage elasticities, the IV method can also be challenged on econometric grounds. Qin [17] has recently exposed the nature of the IV route-which amounts to rejecting $\ln \left(w_{i}\right)$ as a valid conditional variable for $H_{i}$ and accepting, instead, $\widehat{\ln \left(w_{i}\right)} I V$, a non-optimal predictor of $\ln \left(w_{i}\right)$. Qin [18] further demonstrates that the validity of the textbook proof of consistency of the IV treatment is limited to bivariate models and does not extend to multivariate models such as (2). Hence, the common practice of using the Durbin-Wu-Hausman endogeneity test on $\hat{\alpha}_{1}^{I V} \neq \hat{\alpha}_{1}^{O L S}$ as empirical verification of the IV treatment is logically inadequate. It is a primary task of applied modellers to determine whether $\ln \left(w_{i}\right)$ can be rejected as a valid conditional variable in favour of a non-optimal predictor of it, $\left.\widehat{\ln \left(w_{i}\right)}\right)_{I V}$, as specified in (2), and also whether the IV estimates of (2) exhibit any convergence with increasing sample sizes. Since neither issue has been attended in the existent findings of IV-based

4 This can be seen from both the wide adoption of Mroz's [19] study in econometrics textbooks, e.g., [20], and the extensive use of IV and 2SLS methods in labour economics research, see [21]. 
"shrinking elasticities", we take on the task here using cross-section samples from both the CPS and the PSID. Since the coverage of the CPS is much wider than that of the PSID, a comparative study from the two sources should shed light not only on whether consistency holds for $\hat{\alpha}_{1}^{I V}$ but also on whether there is noticeable selection bias in sampling.

The first issue of our investigation is the validity of IV estimates by over-identification restriction tests as well as constancy across two samples of the same wave. To circumvent the non-unique choices of IVs, we choose them in reference to [5,6], and aim at mimicking their estimated $\hat{\alpha}_{1}^{I V}$ for three waves-1980, 1990, 2000. ${ }^{5}$ Specifically, two groups of experiments are produced. The first group is carried out aiming for a set of IVs which would get us close to the results presented by the above two empirical studies using the CPS data, and apply the same set of instruments to the PSID data. The second group is to seek a set of IVs for the same purpose using the PSID data alone. Table 1 provides the key results of these experiments.

Several common features are discernible from Table 1. It is not difficult to find $\hat{\alpha}_{1}^{I V}$ using the CPS samples which corroborate our targeted values even though our model does not have exactly the same variable coverage as in $[5,6]$ (see the two CPS columns). However, the corroboration is not reproducible when we apply the same IV set to the PSID data of the same waves (see columns 2 and 5). Since the CPS surveys should be adequately representative with respect to the PSID surveys, this finding indicates absence of consistency in $\hat{\alpha}_{1}^{I V}$. Nevertheless, corroboration of the targeted values is still achievable through alteration of the IV set (see columns 3 and 6). These experiments clearly demonstrate the non-uniqueness of the IV route. As expected, $\widehat{\ln \left(w_{i}\right)}$ IV obtained from the various sets of the first-stage of the IV procedure are substantially different from $\ln \left(w_{i}\right)$, as easily seen from those small adjusted $R^{2}$ statistics reported in Table 1, in spite of that equation being "over-identified". Consequently, the Durbin-Wu-Hausman endogeneity test statistics endorse the IV estimates for the majority of cases for being different from the OLS estimates. However, the Sargan over-identification restriction test is rejected dominantly, invalidating all of the four IV sets. The rejection comes unsurprisingly since $Z \cap\{\ln (I), X\} \neq 0$ for all our IV sets, though violation of the correlation condition is somewhat eased by taking quadratic or cubit forms of the overlapping variables.

It is noticeable from Table 1 that those IV estimates with selection-bias corrections do not show much statistically significant difference as compared with the general varied ranges of IV estimates (compare the two CPS columns, or columns 2 and 5 in the PSID case). This finding corroborates many previous findings including [5] and [24]. The virtually irrelevance of Heckman's self-selection-bias correction is actually implied in the IV-based model (2), where the correction amounts to adding one more instrument, $\rho$, in the already over-identified IV set, $Z$. Furthermore, this additional instrument, $\rho$, is derived from instruments, $Y$, which carry notably overlapping information with $Z$. It should also be noted that Heckman's method targets, on the assumption that selection bias exists, narrowly at the possible OLS bias in estimating $\lambda_{i k}$ in the IV equation of (2) and treats the bias as a special type of omitted variable bias (OVB) (see [25]). However, this correction is virtually beside the point in view of estimating our parameter of interest, $\alpha_{1}$. Numerous empirical model results tell us that the estimates of $\alpha_{1}$ are sensitive to the choice of $\left.\widehat{\ln \left(w_{i}\right)}\right)_{I V}$, as illustrated in Table 1. In contrast, $\left.\widehat{\ln \left(w_{i}\right)}\right)_{I V}$ is usually not sensitive, as measured either by the adjusted $R^{2}$ or any information criteria, to whether the estimated $\lambda_{i k}$ suffer from OVB due to missing $\rho$, especially when $\rho$ is based on heavily overlapping $\mathrm{Z}$ and $\{\ln (I), Y\} .6$

5 As explained in footnote 3, we take 1999 wave here as a proxy for 2000, due to the fact that the PSID source does not have 2000 survey.

6 This is a problem of multicollinearity as formally demonstrated by Puhani [26], whereas the similarity of the Heckman correction to the simple OLS correction is shown by Olsen [27]. 
Table 1. Instrumental variables (IV) estimates of $\alpha_{1}$ in model (2) and related statistics, working wife samples.

\begin{tabular}{|c|c|c|c|c|c|c|c|}
\hline \multicolumn{2}{|c|}{ Calibration Case } & \multicolumn{3}{|c|}{ Blau and Kahn [5] (Model 4, Table 6) } & \multicolumn{3}{|c|}{ Heim [6] (Table 1) } \\
\hline \multirow{2}{*}{\multicolumn{2}{|c|}{ IVs }} & CPS & PSID & PSID & CPS & PSID & PSID \\
\hline & & \multicolumn{2}{|c|}{ Set 1} & Set 2 & \multicolumn{2}{|c|}{ Set 3} & Set 4 \\
\hline \multirow{7}{*}{1980} & Target & \multicolumn{3}{|c|}{$\hat{\alpha}_{1}^{I V} \approx 366.4=0.252 \times 1454$} & \multicolumn{3}{|c|}{$\hat{\alpha}_{1}^{I V}=533.7,95 \%$ C.I. $(-128.7,1196.1)$} \\
\hline & $\alpha_{1}^{I V}$ & $314.29 * *$ & -166.40 & $223.0 * *$ & $332.24 * *$ & $-166.98 *$ & $295.2 * *$ \\
\hline & 95\% C.I. & $(233,396)$ & $(-333,0.47)$ & $(62.4,384)$ & $(251,413)$ & $(-333,-1.2)$ & $(130,460)$ \\
\hline & Hausman & $17.67^{* *}$ & $16.89 * *$ & 1.459 & $21.91 * *$ & $17.03^{* *}$ & $4.69 *$ \\
\hline & $1 \mathrm{st}$ adj. $R^{2}$ & 0.116 & 0.193 & 0.181 & 0.118 & 0.193 & 0.174 \\
\hline & Over-id. & $118.26^{* *}$ & $17.81^{* *}$ & $75.45^{* *}$ & $139.10^{* *}$ & $17.82^{* *}$ & $65.31 * *$ \\
\hline & Elasticity & 0.210 & -0.111 & 0.149 & 0.222 & -0.111 & 0.197 \\
\hline \multirow{7}{*}{1990} & Target & \multicolumn{3}{|c|}{$\hat{\alpha}_{1}^{I V} \approx 352.7=0.216 \times 163$} & \multicolumn{3}{|c|}{$\hat{\alpha}_{1}^{I V}=534,95 \%$ C.I. $(124.8,943.2)$} \\
\hline & $\alpha_{1}^{I V}$ & $317.371^{* *}$ & 79.63 & $328.29 * *$ & $318.2681 * *$ & 68.339 & $385.93^{* *}$ \\
\hline & 95\% C.I. & $(265,370)$ & $(-15.1,174)$ & $(224,423)$ & $(266,370)$ & $(-26.1,163)$ & $(287,485)$ \\
\hline & Hausman & $15.331^{* *}$ & $5.8480 *$ & $13.125^{* *}$ & $15.664^{* *}$ & $7.3365^{* *}$ & $23.437^{* *}$ \\
\hline & $1 \mathrm{st}$ adj. $R^{2}$ & 0.199 & 0.262 & 0.242 & 0.198 & 0.265 & 0.229 \\
\hline & Over-id. & $78.56^{* *}$ & $19.841^{* *}$ & $68.957 * *$ & $86.565^{* *}$ & $23.691^{* *}$ & $63.578^{* *}$ \\
\hline & Elasticity & 0.2116 & 0.0531 & 0.219 & 0.2122 & 0.0456 & 0.2573 \\
\hline \multirow{7}{*}{1999} & Target & \multicolumn{3}{|c|}{$\hat{\alpha}_{1}^{I V} \approx 213.3=0.122 \times 1748$} & \multicolumn{3}{|c|}{$\hat{\alpha}_{1}^{I V}=303.7,95 \%$ C.I. $(-161.3,768.7)$} \\
\hline & $\alpha_{1}^{I V}$ & $259.362^{* *}$ & 82.727 & $221.75^{* *}$ & $262.9916^{* *}$ & 81.3817 & $267.82 * *$ \\
\hline & 95\% C.I. & $(209,310)$ & $(-30.6,196)$ & $(111,333)$ & $(213,313)$ & $(-32,195)$ & $(149,387)$ \\
\hline & Hausman & $22.294^{* *}$ & 0.461 & $4.412 *$ & $23.854^{* *}$ & 0.499 & $7.364 * *$ \\
\hline & 1st adj. $R^{2}$ & 0.2078 & 0.2320 & 0.2194 & 0.2080 & 0.2317 & 0.218 \\
\hline & Over-id. & $84.89 * *$ & $31.32 * *$ & $30.72 * *$ & $91.93 * *$ & $32.55^{* *}$ & $14.14^{* *}$ \\
\hline & Elasticity & 0.173 & 0.055 & 0.148 & 0.175 & 0.054 & 0.179 \\
\hline \multirow{6}{*}{2003} & $\alpha_{1}^{I V}$ & $207.1^{* *}$ & $172.87^{* *}$ & $314.07^{* *}$ & $207.74^{* *}$ & $177.39^{* *}$ & $344.12 * *$ \\
\hline & 95\% C.I. & $(169,245)$ & $(35.2,311)$ & $(178,450)$ & $(170,246)$ & $(42.6,312)$ & $(200,488)$ \\
\hline & Hausman & $22.567 * *$ & 3.6356 & $19.1^{* *}$ & $22.935 * *$ & $4.0707^{*}$ & $23.138^{* *}$ \\
\hline & 1 st adj. $R^{2}$ & 0.2164 & 0.2001 & 0.1823 & 0.2038 & 0.1998 & 0.1806 \\
\hline & Over-id. & $168.77^{* *}$ & $19.61^{* *}$ & $19.75^{* *}$ & $170.09 * *$ & $19.78^{* *}$ & $13.02 * *$ \\
\hline & Elasticity & 0.138 & 0.115 & 0.209 & 0.140 & 0.118 & 0.229 \\
\hline \multirow{6}{*}{2007} & $\alpha_{1}^{I V}$ & $178.55^{* *}$ & 92.669 & $217.796^{* *}$ & $178.267^{* *}$ & 86.893 & $296.759^{* *}$ \\
\hline & 95\% C.I. & $(142,215)$ & $(-20.7,206)$ & $(96.9,339)$ & $(142,215)$ & $(-25.9,200)$ & $(163,431)$ \\
\hline & Hausman & $9.562 * *$ & 0.018 & 5.923 * & $9.470 * *$ & 0.001 & 13.32 ** \\
\hline & $1 \mathrm{st}$ adj. $R^{2}$ & 0.220 & 0.229 & 0.186 & 0.212 & 0.229 & 0.175 \\
\hline & Over-id. & $155.41^{* *}$ & 26.18 ** & $47.48^{* *}$ & $155.67^{* *}$ & $26.43 * *$ & $32.73^{* *}$ \\
\hline & Elasticity & 0.119 & 0.062 & 0.145 & 0.119 & 0.058 & 0.198 \\
\hline \multirow{6}{*}{2011} & $\alpha_{1}^{I V}$ & $292.8^{* *}$ & $331.814^{* *}$ & 423.402 ** & $292.306^{* *}$ & $335.46^{* *}$ & 437.553 \\
\hline & 95\% C.I. & $(256,330)$ & $(202,461)$ & $(289,558)$ & $(255,329)$ & $(206,465)$ & $(300,575)$ \\
\hline & Hausman & $68.682^{* *}$ & $11.234^{* *}$ & 23.28 ** & $68.682 * *$ & $11.7021^{* *}$ & $25.19 * *$ \\
\hline & $1 \mathrm{st}$ adj. $R^{2}$ & 0.245 & 0.185 & 0.162 & 0.228 & 0.185 & 0.168 \\
\hline & Over-id. & $111.62^{* *}$ & 7.9784 & $29.226 * *$ & 113.109 ** & 9.1695 & $26.2 * *$ \\
\hline & Elasticity & 0.195 & 0.221 & 0.282 & 0.195 & 0.224 & 0.292 \\
\hline
\end{tabular}

C.I. stands for confidence interval; Hausman is the Wu-Hausman test of endogeneity; Over-id. stands for Sargan over identification tests; ** and * indicate significance level at $1 \%$ and $5 \%$ respectively; 1 st adj. $R^{2}$ stands for adjusted $R^{2}$ of the first stage regression from the 2SLS/IV procedure; IV set 1: Husband's education, husband's wage rate in $\log$, wife's education, wife's education in quadratic and cubic forms; IV set 2: Wife's education, its quadratic and cubic forms, wife's previous years of work, wife's age in cubic form; IV set 3: Same IVs as in Set 1 plus inverse Mill's ratio conditional on family non-wife income in log, wife's education, wife's age in cubic, number of children, presence of children under 6; IV set 4: Wife's education, wife's previous years of work, wife's age in cubic form and the same inverse Mill's ratio as in Set 3. Elasticity is evaluated at $1500 \mathrm{~h}$. 
Conceptually, substantive concern over selection bias is with respect to the "missing" offering wage rate of those wives reported not working, i.e., possible "selection bias" due to the truncation effect in $H_{i} .{ }^{7}$ In order to assess this effect via nonlinear estimation such as tobit, we need to impute the "missing" offering wage rates. Considering the unsatisfactorily low fit of various regression models or likelihood based methods previously used in the literature, we decide to use the hot deck imputation method to impute the missing offering wage rates. This method has been widely used by statisticians for handling missing data, e.g., see [28], and can be seen as a systematic extension to the method used by Blau and Kahn [5]. The details of our imputation are described in Appendix A.2.

Once those "missing" offering wage rates are imputed, we re-estimate (2) with the IV tobit method using extended data samples including those wives having zero work hours. The main results are summarised in Table 2.

Table 2. IV tobit estimates of $\alpha_{1}$ in model (2) and related statistics using the same IV sets as in Table 1, full samples including non-working wives.

\begin{tabular}{|c|c|c|c|c|c|c|c|}
\hline & \multirow{2}{*}{ IVs } & CPS & PSID & PSID & CPS & PSID & PSID \\
\hline & & Set 1 & & Set 2 & Set 3 & & Set 4 \\
\hline \multirow{4}{*}{1980} & $\alpha_{1}^{I V T B}$ & 1103.22 & 722.38 & 1260.62 & 1162.553 & 734.9121 & 1408.975 \\
\hline & 95\% C.I. & $(1038,1169)$ & $(529,916)$ & $(1070,1451)$ & $(1099,1226)$ & $(542,928)$ & $(1204,1614)$ \\
\hline & Wald & $18.99 * *$ & 3.14 & $80.16^{* *}$ & $6.21 *$ & 3.83 & $103.36^{* *}$ \\
\hline & Over-id. & $297.854^{* *}$ & $34.789 * *$ & $152.895^{* *}$ & $353.823 * *$ & $48.346^{* *}$ & $121.252 * *$ \\
\hline \multirow{4}{*}{1990} & $\alpha_{1}^{I V T B}$ & 768.3579 & 596.1497 & 1090.07 & 777.22 & 600.07 & 1246.528 \\
\hline & 95\% C.I. & $(730,807)$ & $(482,711)$ & $(981,1199)$ & $(739,815)$ & $(486,714)$ & $(1128,1365)$ \\
\hline & Wald & 91.83 ** & 0.54 & $112.53^{* *}$ & $83.67^{* *}$ & 0.43 & $172.53^{* *}$ \\
\hline & Over-id. & $225.775^{* *}$ & $77.268^{* *}$ & $266.414^{* *}$ & $237.921 * *$ & $77.815^{* *}$ & $165.987^{* *}$ \\
\hline \multirow{4}{*}{1999} & $\alpha_{1}^{I V T B}$ & 674.6063 & 508.9325 & 784.589 & 680.8055 & 515.2407 & 930.1164 \\
\hline & 95\% C.I. & $(637,712)$ & $(372,646)$ & $(648,922)$ & $(644,718)$ & $(378,653)$ & $(782,1078)$ \\
\hline & Wald & 89.34 ** & 0.02 & 23.91 ** & $83.08^{* *}$ & 0.07 & $46.72 * *$ \\
\hline & Over-id. & $175.907^{* *}$ & $66.341^{* *}$ & $115.620 * *$ & $187.119^{* *}$ & $68.125^{* *}$ & $64.593 * *$ \\
\hline \multirow{4}{*}{2003} & $\alpha_{1}^{I V T B}$ & 626.9265 & 492.3992 & 763.7196 & 627.5508 & 517.1577 & 864.2152 \\
\hline & 95\% C.I. & $(598,656)$ & $(338,647)$ & $(614,913)$ & $(599,656)$ & $(365,670)$ & $(706,1023)$ \\
\hline & Wald & $169.57^{* *}$ & 0.00 & $16.64^{* *}$ & $167.73^{* *}$ & 0.11 & $27.80 * *$ \\
\hline & Over-id. & $384.788^{* *}$ & $28.452^{* *}$ & 71.022 ** & $386.904^{* *}$ & $32.104^{* *}$ & $48.613^{* *}$ \\
\hline \multirow{4}{*}{2007} & $\alpha_{1}^{I V T B}$ & 624.1504 & 485.6784 & 677.1806 & 623.2197 & 485.0906 & 851.3809 \\
\hline & 95\% C.I. & $(597,651)$ & $(348,623)$ & $(534,820)$ & $(596,651)$ & $(350,621)$ & $(692,1011)$ \\
\hline & Wald & $159.96^{* *}$ & 0.01 & $9.45^{* *}$ & $161.11^{* *}$ & 0.01 & $26.88^{* *}$ \\
\hline & Over-id. & $448.117^{* *}$ & $54.741^{* *}$ & $99.299 * *$ & $447.535^{* *}$ & $54.743^{* *}$ & $59.157^{* *}$ \\
\hline \multirow{4}{*}{2011} & $\alpha_{1}^{I V T B}$ & 645.2837 & 850.8864 & 1004.48 & 644.3989 & 860.8814 & 1047.094 \\
\hline & 95\% C.I. & $(620,671)$ & $(702,1000)$ & $(853,1157)$ & $(619,670)$ & $(712,1010)$ & $(890,1204)$ \\
\hline & Wald & $143.01^{* *}$ & $11.13^{* *}$ & $31.44^{* *}$ & $144.24^{* *}$ & $12.36^{* *}$ & $36.83 * *$ \\
\hline & Over-id. & $238.034^{* *}$ & $31.499 * *$ & $48.468^{* *}$ & $238.488^{* *}$ & $36.007^{* *}$ & $39.539 * *$ \\
\hline
\end{tabular}

C.I. stands for confidence interval; Wald is the Wald test of exogeneity; Over-id. stands for Sargan over-identification tests; ${ }^{* *}$ and ${ }^{*}$ indicate significance at $1 \%$ and $5 \%$ respectively. IV sets are identical to those in Table 1. Elasticity is evaluated at $1500 \mathrm{~h}$.

It is remarkable how substantially different the IV estimates are as compared to those reported in Table 1. Again, there lacks strong agreement in estimates of the same wave between the CPS and the

7 It is debatable whether we should use model (1) to characterise the labour supply behaviour of both the working group and non-working group. The truncation effect would not matter here if we assume that wage effect on hours of work differ from that on the labour force participation. This assumption finds support from our subsequent experiment reported in Section 3. Nevertheless, we have tried the tobit route following [5]. 
PSIS sources. The only feature which remains unchanged is the wide acceptance of the "endogeneity" test jointly with sweeping rejection of the over-identification restrictions. Since the truncation effect on the OLS bias has been shown to be approximately a rescale effect by the shares of the truncated observations in a truncated sample (see $[29,30]$ ), we re-run the extended samples simply by the tobit and the OLS, and then calculate the scaled OLS estimates. As seen from Table 3, the scaled OLS estimates are indeed very similar to the tobit estimates.

Table 3. Tobit estimates of $\alpha_{1}$ in model (1), the corresponding OLS and scaled OLS estimates.

\begin{tabular}{cccccccc}
\hline & & \multicolumn{2}{c}{ Tobit } & \multicolumn{2}{c}{ OLS } & \multicolumn{2}{c}{ Scaled OLS } \\
\cline { 3 - 7 } & & PSID & CPS & PSID & CPS & PSID & CPS \\
\hline \multirow{2}{*}{1980} & $\alpha_{1}^{T B}$ & 380.931 & -370.906 & 283.254 & -169.7745 & 405.808 & -265.796 \\
& $95 \%$ C.I. & $(295,467)$ & $(-407,-335)$ & $(221,345)$ & $(-192,-148)$ & & \\
\hline \multirow{2}{*}{1990} & $\alpha_{1}^{T B}$ & 437.991 & 338.016 & 351.125 & 284.513 & 452.714 & 382.385 \\
& $95 \%$ C.I. & $(374,502)$ & $(307,369)$ & $(298,404)$ & $(259,310)$ & & \\
\hline \multirow{2}{*}{1999} & $\alpha_{1}^{T B}$ & 393.458 & 106.9957 & 312.449 & 109.0798 & 390.561 & 142.368 \\
& $95 \%$ C.I. & $(326,461)$ & $(74,140)$ & $(246,379)$ & $(83,135)$ & & \\
\hline \multirow{2}{*}{2003} & $\alpha_{1}^{T B}$ & 430.031 & -183.6984 & 327.306 & -104.1236 & 397.699 & -137.519 \\
& $95 \%$ C.I. & $(354,507)$ & $(-209,-159)$ & $(262,393)$ & $(-123,-85)$ & & \\
\hline \multirow{2}{*}{2007} & $\alpha_{1}^{T B}$ & 421.387 & 38.39097 & 330.237 & 53.65889 & 400.287 & 71.353 \\
& $95 \%$ C.I. & $(347,496)$ & $(13,64)$ & $(267,394)$ & $(34,73)$ & & \\
\hline \multirow{2}{*}{2011} & $\alpha_{1}^{T B}$ & 560.137 & -64.5882 & 434.183 & -15.6025 & 538.689 & -21.054 \\
& $95 \%$ C.I. & $(485,636)$ & $(-93,-37)$ & $(372,497)$ & $(-37,5.8)$ & & \\
\hline
\end{tabular}

C.I. stands for confidence interval.

The extra amount of variations in IV tobit estimates in Table 2 as compared to those in Table 1 cannot be possibly accounted for as the truncation effect. The non-optimality of this IV route is too apparent to deserve further comments.

Next, we examine the degree of simultaneity between $\ln \left(w_{i}\right)$ and $H_{i}$ by running the following simultaneous equation model (SEM):

$$
\begin{gathered}
H_{i}=\alpha_{0}+\alpha_{1} \ln \left(w_{i}\right)+\alpha_{2} \ln \left(I_{i}\right)+\sum_{j} \beta_{j} X_{i j}+\varepsilon_{i} \\
\ln \left(w_{i}\right)=\gamma_{0}+\gamma_{1} H_{i}+\sum_{k} \delta_{k} Z_{i k}+v_{i}
\end{gathered}
$$

and estimate it by the FIML (full-information maximum likelihood) method, although we do not anticipate much simultaneity from economic reasoning. Notice, (4) augments (2) by adding $H_{i}$ in its second equation. Hence, over-identification restriction tests still apply here. Table 4 reports the main results of this experiment.

Again, the over-identification restriction test is rejected in all cases. Notice that more than half of the cases fail to demonstrate the presence of significant simultaneity between $\alpha_{1}$ and $\gamma_{1}$ estimates. Worse still, the majority of the wage parameter estimates are now negative, making them far less credible than those IV estimates given in Table 1. In fact, the incredibility of these SEM results has been exposed repeatedly before in macro-econometrics, e.g., [31,32]. In particular, the insurmountable gap between reality and those over-identification restrictions used to circumvent endogeneity bias created by simple model formulation has been forcefully criticised (see [32]). 
Table 4. Full-information maximum likelihood (FIML) estimates of $\alpha_{1}$ for $\ln \left(w_{i}\right)$ and $\gamma_{1}$ for $h_{i}$ in model (4) and related statistics.

\begin{tabular}{|c|c|c|c|c|c|}
\hline & & \multicolumn{2}{|c|}{ Working Women Sample Without SB } & \multicolumn{2}{|c|}{ Full Sample with Non-workers Without SB } \\
\hline & & PSID & CPS & PSID & CPS \\
\hline \multirow{5}{*}{1980} & $\alpha_{1}^{M L}$ & -663.988 & -390.794 & -266.489 & -825.867 \\
\hline & $t$-stat & $-3.27 * *$ & $-4.81^{* *}$ & -1.62 & $-9.02 * *$ \\
\hline & $\gamma_{1}^{M L}$ & 0.00022 & 0.000295985 & 0.00011 & 0.000112739 \\
\hline & $t$-stat ${ }^{\wedge}$ & $2.78^{* *}$ & 11.40 ** & $2.88^{* *}$ & $6.64 * *$ \\
\hline & Over-id. & $28.647[0.0001]^{* *}$ & $73.122[0.0000]$ ** & $31.943[0.0000]^{* *}$ & $124.60[0.0000]^{* *}$ \\
\hline \multirow{5}{*}{1990} & $\alpha_{1}^{M L}$ & -287.037 & -74.0089 & -181.509 & -182.757 \\
\hline & $t$-stat & $-2.82 * *$ & -1.42 & -1.92 & $-3.01 * *$ \\
\hline & $\gamma_{1}^{M L}$ & 0.00027 & 0.000258521 & 0.00022 & 0.000155719 \\
\hline & $t$-stat & $4.33^{* *}$ & $9.90 * *$ & $6.19 * *$ & $9.06 * *$ \\
\hline & Over-id. & $31.396[0.0000]^{* *}$ & $110.23[0.0000]^{* *}$ & $31.549[0.0000]^{* *}$ & $138.42[0.0000]^{* *}$ \\
\hline \multirow{5}{*}{1999} & $\alpha_{1}^{M L}$ & -609.557 & -211.142 & -377.825 & -402.726 \\
\hline & $t$-stat ${ }^{\wedge}$ & $-3.8 * *$ & $-3.31^{* *}$ & $-2.72 * *$ & $-5.22 * *$ \\
\hline & $\gamma_{1}^{M L}$ & 0.000000153 & 0.000206674 & 0.0001 & 0.000115700 \\
\hline & $t$-stat ${ }^{\wedge}$ & 0.00169 & $5.42 * *$ & $2.08^{*}$ & $5.12 * *$ \\
\hline & Over-id. & $16.550[0.0111]^{*}$ & $108.89[0.0000]$ ** & $26.913[0.0002]^{* *}$ & $122.70[0.0000] * *$ \\
\hline \multirow{5}{*}{2003} & $\alpha_{1}^{M L}$ & -164.8 & -351.48 & -63.0877 & -588.229 \\
\hline & $t$-stat & -0.842 & $-6.86^{* *}$ & -0.36 & $-9.25^{* *}$ \\
\hline & $\gamma_{1}^{M L}$ & 0.00004 & 0.000180449 & 0.0001 & 0.0000508823 \\
\hline & $t$-stat ${ }^{\wedge}$ & 0.6354 & $6.03^{* *}$ & 1.99 & $2.90 * *$ \\
\hline & Over-id. & $38.832[0.0000]^{* *}$ & $122.37[0.0000]$ ** & $43.802[0.0000]^{* *}$ & $170.52[0.0000]^{* *}$ \\
\hline \multirow{5}{*}{2007} & $\alpha_{1}^{M L}$ & -214.64 & -266.109 & -162.506 & -548.217 \\
\hline & $t$-stat & -1.79 & $-5.95^{* *}$ & -1.33 & $-8.84^{* *}$ \\
\hline & $\gamma_{1}^{M L}$ & 0.000067 & 0.000173201 & 0.000098 & 0.0000996420 \\
\hline & $t$-stat & 0.523 & $4.93^{* *}$ & 1.69 & $5.12 * *$ \\
\hline & Over-id. & $39.725[0.0000]^{* *}$ & $80.461[0.0000]$ ** & $35.591[0.0000]^{* *}$ & $85.537[0.0000]^{* *}$ \\
\hline \multirow{5}{*}{2011} & $\alpha_{1}^{M L}$ & 219.577 & -78.3481 & 170.565 & -56.3384 \\
\hline & $t$-stat & 1.09 & -1.64 & 0.996 & -0.894 \\
\hline & $\gamma_{1}^{M L}$ & -0.00036 & 0.000116232 & 0.00004 & 0.0000202683 \\
\hline & $t$-stat & $-2.39 *$ & $3.15^{* *}$ & 0.571 & 1.21 \\
\hline & Over-id. & $45.133[0.0000]^{* *}$ & $78.302[0.0000]$ ** & $40.639[0.0000]^{* *}$ & $157.62[0.0000]^{* *}$ \\
\hline
\end{tabular}

C.I. stands for confidence interval; $t$-stat ${ }^{\wedge}$ stands for $t$-test based on HCSE robust standard errors; Over-id. stands for Sargan over-identification tests; ${ }^{* *}$ and * indicate significance level at $1 \%$ and $5 \%$ respectively.

It is further easily noticeable from Tables 1, 2 and 4 how different the IV and FIML estimates can be between the CPS and PSID samples of the same waves. Since parameter invariance is implied by the consistency property and is also the backbone of statistical inference, our next experiment turns to the degrees of within-sample invariance. ${ }^{8}$ This is carried out via recursive estimations and parameter stability tests. However, both the recursive estimation technique and parameter stability tests are predicated on a unique data ordering assumption (e.g., see [34]) while there is no natural data ordering scheme in the cross-section context (e.g., see [35]). Here, we choose the ordering scheme on the basis of two conditions: (a) the ordering scheme complies with the fixed regressor principle, i.e., it is consistent with the model specification; (b) the ordering scheme is substantively meaningful and relevant (see [36] for an exploring experiment with data ordering). Our initial trial is to order data by wife's age, since it is acceptable to treat the age variable as a fixed regressor for both models (1) and (2). Moreover, this ordering scheme can be economically interesting as can be seen from [5] (B3 in Section V) and [37].

8 It should be noted that this condition was central in the original definition of structural relations by Frisch over 80 years ago. It underlies the concept of super-exogeneity in time-series econometrics, and is deemed a strong condition for causal linear stochastic dependence in psychometrics, e.g., see [33]. 
The within-sample invariance of the IV estimates is examined by means of two types of parameter stability tests-the commonly used Hansen test and the M-fluctuation test for individual parameter stability developed by Merkle et al. [38]. The latter is used because the Hansen test is not directly applicable to IV estimators. Specifically, we use the Hansen test to examine how invariant the IV generating process of $\ln \left(\hat{(}_{i}\right)_{I V}$ is, that is, how stable the parameters of the second equation, i.e., the IV equation, of model (2) are. Here, only the joint parameter test statistics are reported in Table 5 to save space.

It is clearly shown in the table that most of the IV generating processes are not within-sample invariant. Next, we apply the M-fluctuation test to all the $\hat{\alpha}_{1}^{I V}$ reported in Table 1 and also to the corresponding $\hat{\alpha}_{1}^{O L S}$ based on model (1). The test results in Table 5 show that the null hypothesis of stability is rejected more often for $\hat{\alpha}_{1}^{I V}$ than for $\hat{\alpha}_{1}^{O L S}$ whereas $\hat{\alpha}_{1}^{I V}$ tends to pass the M-fluctuation test when the test on $\hat{\alpha}_{1}^{O L S}$ shows strong rejection, as visible from the 2003 and 2007 CPS results. The latter observation corroborates directly with Perron and Yamamoto's [39] finding, namely that the IV-based methods have lower power in detecting parameter instability than the OLS-based methods due to the fact that the IV-generated regressors are too smooth to retain enough variations to match those of the modelled variable. The same fact can help explain our former observation as well. Since $\ln \left(w_{i}\right)_{I V}$ carry less variations than $\ln \left(w_{i}\right)$-variations which are needed to explain those in $H_{i}$ - the recursive $\hat{\alpha}_{1}^{I V}$ have to vary more than $\hat{\alpha}_{1}^{O L S}$ in compensation. Consequently, $\hat{\alpha}_{1}^{I V}$ suffer from having much larger standard error bands than $\hat{\alpha}_{1}^{O L S}$ at the same significance level or the same size of the test. To illustrate this situation, we plot in Figure 1 the recursive estimation of $\hat{\alpha}_{1}^{I V}$ with its $95 \%$ confidence interval of the 1999 IV sets reported in Table 1, together with their counterparts of the OLS estimates (the bottom two graphs). The varied and inaccurate as well as prolific properties of the IV estimates are strikingly obvious, especially in comparison to the OLS plots.

Table 5. Parameter Stability tests: (i) the first stage regression to generate $\widehat{\ln \left(w_{i}\right)}$ IV ; (ii) $\alpha_{1}^{I V}$ of model (2) using the same IV sets as in Table 1 ; (iii) $\alpha_{1}^{O L S}$ of model (1), full working wife samples.

\begin{tabular}{|c|c|c|c|c|c|c|c|c|c|}
\hline \multirow{2}{*}{\multicolumn{2}{|c|}{ IVs }} & CPS & PSID & PSID & CPS & PSID & PSID & CPS & PSID \\
\hline & & \multicolumn{2}{|c|}{ Set 1} & Set 2 & \multicolumn{2}{|c|}{ Set 3} & Set 4 & \multicolumn{2}{|c|}{ OLS } \\
\hline \multirow{2}{*}{1980} & Hansen & $7.714^{* *}$ & 0.897 & 1.277 & $11.86^{* *}$ & 1.187 & 1.384 & \multicolumn{2}{|c|}{$\mathrm{N} / \mathrm{A}$} \\
\hline & $\begin{array}{l}\text { M-fluct. } \\
\text { ( } p \text {-value) }\end{array}$ & $\begin{array}{l}2.288 * * \\
(0.0000)\end{array}$ & $\begin{array}{c}1.236 \\
(0.094)\end{array}$ & $\begin{array}{c}0.714 \\
(0.6875)\end{array}$ & $\begin{array}{l}2.394^{* *} \\
(0.0000)\end{array}$ & $\begin{array}{c}1.245 \\
(0.0899)\end{array}$ & $\begin{array}{c}0.868 \\
(0.4389)\end{array}$ & $\begin{array}{c}1.263 \\
(0.0822)\end{array}$ & $\begin{array}{c}0.700 \\
(0.7108)\end{array}$ \\
\hline \multirow{2}{*}{1990} & Hansen & $11.50^{* *}$ & $2.760 * *$ & $3.059 * *$ & $14.79 * *$ & $3.713^{* *}$ & $3.181^{* *}$ & \multicolumn{2}{|c|}{$\mathrm{N} / \mathrm{A}$} \\
\hline & $\begin{array}{l}\text { M-fluct. } \\
\text { ( } p \text {-value) }\end{array}$ & $\begin{array}{c}1.0649 \\
(0.2068)\end{array}$ & $\begin{array}{l}1.629 * * \\
(0.0099)\end{array}$ & $\begin{array}{l}1.3849 * \\
(0.0432)\end{array}$ & $\begin{array}{c}1.0951 \\
(0.1816)\end{array}$ & $\begin{array}{c}1.5676^{*} \\
(0.0147)\end{array}$ & $\begin{array}{c}1.1185 \\
(0.1637)\end{array}$ & $\begin{array}{c}0.9612 \\
(0.3139)\end{array}$ & $\begin{array}{c}0.9392 \\
(0.3409)\end{array}$ \\
\hline \multirow{2}{*}{1999} & Hansen & $10.56^{* *}$ & $5.458 * *$ & 1.8842 & $11.47^{* *}$ & $5.974^{* *}$ & $1.8770 *$ & \multicolumn{2}{|c|}{$\mathrm{N} / \mathrm{A}$} \\
\hline & $\begin{array}{l}\text { M-fluct. } \\
\text { ( } p \text {-value) }\end{array}$ & $\begin{array}{l}1.956 * * \\
(0.001)\end{array}$ & $\begin{array}{l}1.5463 * \\
(0.0168)\end{array}$ & $\begin{array}{l}1.640 * * \\
(0.0092)\end{array}$ & $\begin{array}{l}1.966^{* *} \\
(0.0009)\end{array}$ & $\begin{array}{l}1.554 * \\
(0.016)\end{array}$ & $\begin{array}{l}1.5426 * \\
(0.0171)\end{array}$ & $\begin{array}{c}0.6965 \\
(0.7171)\end{array}$ & $\begin{array}{c}0.755 \\
(0.6188) \\
\end{array}$ \\
\hline \multirow{2}{*}{2003} & Hansen & $8.507^{* *}$ & $3.591^{* *}$ & $1.9347^{*}$ & $9.438^{* *}$ & $3.915^{* *}$ & $1.8215^{*}$ & \multicolumn{2}{|c|}{$\mathrm{N} / \mathrm{A}$} \\
\hline & $\begin{array}{l}\text { M-fluct. } \\
\text { ( } p \text {-value) }\end{array}$ & $\begin{array}{l}2.183^{* *} \\
(0.0001)\end{array}$ & $\begin{array}{c}0.7086 \\
(0.6969)\end{array}$ & $\begin{array}{c}0.9672 \\
(0.3069)\end{array}$ & $\begin{array}{l}2.180 * * \\
(0.0001)\end{array}$ & $\begin{array}{l}0.7596 \\
(0.611)\end{array}$ & $\begin{array}{c}0.9239 \\
(0.3606)\end{array}$ & $\begin{array}{l}1.638^{* *} \\
(0.0093)\end{array}$ & $\begin{array}{c}1.43 * \\
(0.0334)\end{array}$ \\
\hline \multirow{2}{*}{2007} & Hansen & $6.293^{* *}$ & $2.614^{* *}$ & $3.321 * *$ & $6.903^{* *}$ & $3.293^{* *}$ & $3.280 * *$ & \multicolumn{2}{|c|}{$\mathrm{N} / \mathrm{A}$} \\
\hline & $\begin{array}{l}\text { M-fluct. } \\
\text { ( } p \text {-value) }\end{array}$ & $\begin{array}{c}1.2126 \\
(0.1056)\end{array}$ & $\begin{array}{l}0.9086 \\
(0.381)\end{array}$ & $\begin{array}{c}0.668 \\
(0.7637)\end{array}$ & $\begin{array}{l}1.2081 \\
(0.108)\end{array}$ & $\begin{array}{c}0.89 \\
(0.4066)\end{array}$ & $\begin{array}{c}0.7072 \\
(0.6991)\end{array}$ & $\begin{array}{l}1.770 * * \\
(0.0038)\end{array}$ & $\begin{array}{c}0.4358 \\
(0.9913)\end{array}$ \\
\hline \multirow{2}{*}{2011} & Hansen & 7.339 ** & $4.836^{* *}$ & $2.0595 *$ & $7.950 * *$ & $4.887^{* *}$ & $1.8507 *$ & \multicolumn{2}{|c|}{$\mathrm{N} / \mathrm{A}$} \\
\hline & $\begin{array}{l}\text { M-fluct. } \\
\text { ( } p \text {-value) }\end{array}$ & $\begin{array}{l}1.3061 \\
(0.066)\end{array}$ & $\begin{array}{c}0.5972 \\
(0.8679)\end{array}$ & $\begin{array}{l}0.6583 \\
(0.779)\end{array}$ & $\begin{array}{c}1.3134 \\
(0.0635)\end{array}$ & $\begin{array}{l}0.5838 \\
(0.885)\end{array}$ & $\begin{array}{c}0.6501 \\
(0.7919)\end{array}$ & $\begin{array}{c}1.1847 \\
(0.1208)\end{array}$ & $\begin{array}{l}1.6098 \text { * } \\
(0.0112)\end{array}$ \\
\hline
\end{tabular}

Hansen stands for the joint Hansen parameter stability test for all the $\lambda \mathrm{s}$ and $\sigma_{u_{i}}$ in the lower equation of model (2) which generates $\widehat{\ln \left(w_{i}\right)}$ IV $;$ M-fluct. stands for the double maximum statistics(DM) M-fluctuation test for parameter stability by Merkle et al. [38]; ${ }^{*}$ and ${ }^{* *}$ indicate significance level at $5 \%$ and $1 \%$ respectively. 

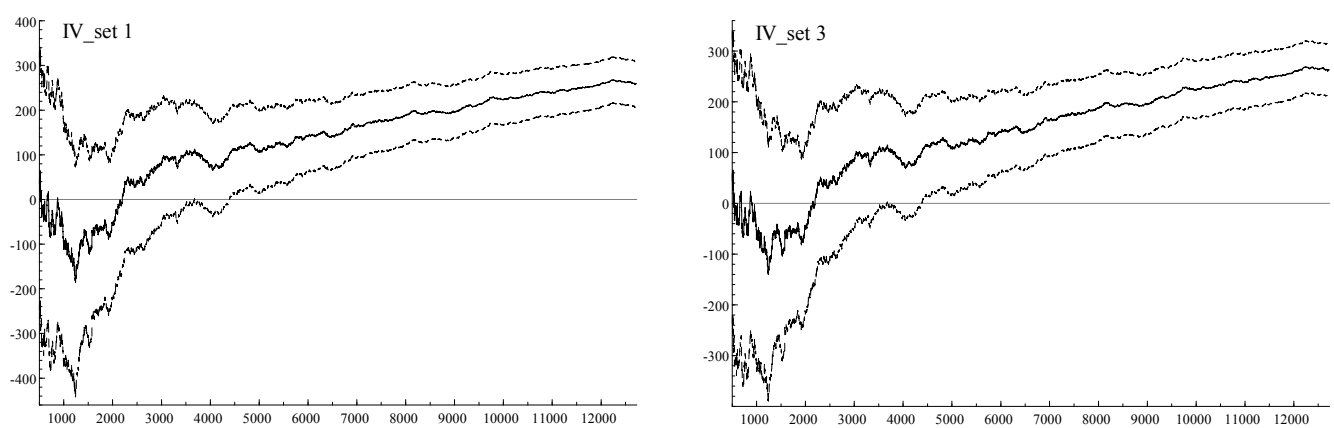

(a)
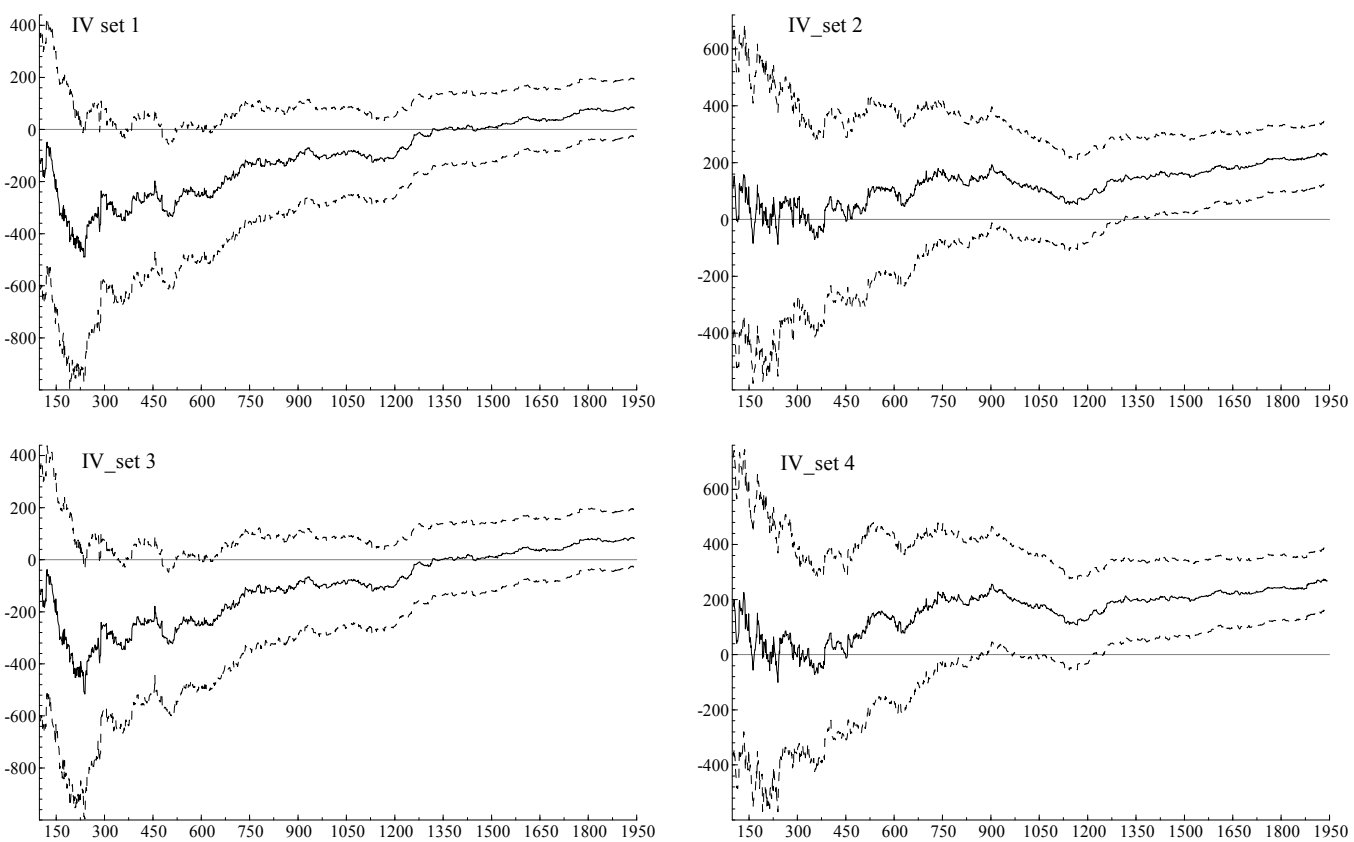

(b)
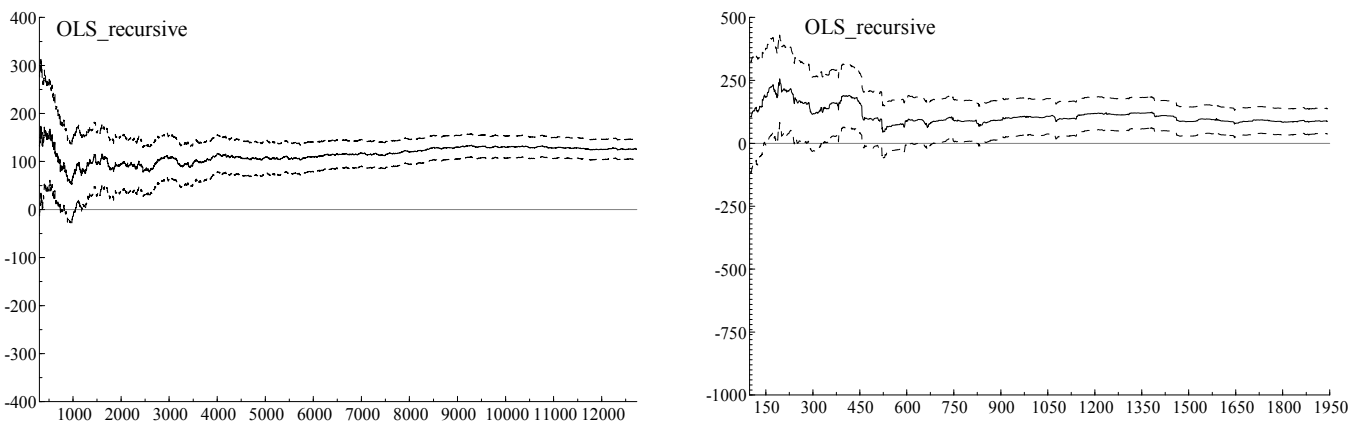

(c)

Figure 1. (a) IV Estimation using Current Population Survey (CPS) Data; (b) IV Estimation using Panel Study of Income Dynamics (PSID) Data; (c) OLS Estimation (Left: CPS Data, Right: PSID Data).

The above investigation provides us with abundant evidence to refute $\hat{\alpha}_{1}^{I V}$ being consistent and refute $\widehat{\ln \left(w_{i}\right)}$ IV being a valid conditional variable instead of $\ln \left(w_{i}\right) .{ }^{9}$ In other words, we have failed

9 This finding coincides with the views by several other authors, who came to call for caution using IVs (e.g., [40]). 
to find adequate and convincing evidence to support the superiority of models (2) and (4) over (1). As a result, the existent IV-based evidence of shrinking elasticities has little credibility.

\section{How Can We Find Credible Elasticities?}

The above findings are apparently devastating, as they throw us back to the "first generation studies" of labour supply over four decades ago, as described in [20] (Chapter 11), and pose serious doubts about the micro-econometrics textbook approach. Methodological issues aside, how should we proceed based on the above results?

The preceding within sample parameter stability experiment indicates a possible way forward-sample data ordering. Considering that our focus on $\alpha_{1}$ is driven by the need of finding the best possible estimates for the own wage elasticity:

$$
\eta_{w}=\frac{\partial H_{i}}{\partial w_{i}} \frac{w_{i}}{H_{i}} \approx \hat{\alpha}_{1} \frac{1}{\bar{H}_{i}}
$$

the closest measurement to (5) should be based on the data ordering scheme by $w_{i}$. In other words, $\eta_{w}$, defined as the percentage change in $H_{i}$ in response to a one percent change in $w_{i}$ is best reflected when data is order by $w_{i}$ so that the incremental change of $w_{i}$ is revealed. This ordering scheme clearly satisfies condition (b) stated in the previous section. Condition (a) requires $w_{i}$ not to be simultaneously determined by $H_{i}$. Data evidence has failed to show any systematic simultaneity so far (cf. Table 4).

With respect to Equation (5), it is obviously better to work with the following log-linear model instead of (1):

$$
\ln \left(H_{i}\right)=a+\eta_{w} \ln \left(w_{i}\right)+\eta_{I} \ln \left(I_{i}\right)+\sum_{j} b_{j} X_{i j}+e_{i}
$$

The use of semi-log specification in (1) is mainly due to the truncated data feature of $H_{i}$. But since we know that the truncation effect can be reasonably well approximated by scaling the OLS estimates, as shown from Table 3, we should be able to leave aside the truncation issue for the time being and focus our experiment on data ordering using the working wife sample only. ${ }^{10}$

Two versions of $\left(1^{\prime}\right)$ are estimated with different specifications of $I_{i}$. For one specification the husband's wage rate and for the other the family income net of the wife's earning is used. This is because $\ln \left(w_{i}\right)$ is usually the most susceptible to the collinear effect by $\ln \left(I_{i}\right)$ among all the explanatory variables in $\left(1^{\prime}\right) .{ }^{11}$ The resulting $\hat{\eta}_{w}^{O L S}$ and their related statistics are reported in Tables 6 and 7. It is clear from Table 6 that different choice of $\ln \left(I_{i}\right)$ do not significantly affect $\hat{\eta}_{w}^{\text {OLS }}$. We thus keep the following modelling experiments on using the family income as $I_{i}$.

The probably most noticeable changes in Table 7 are the Hansen parameter stability test statistics under different data ordering schemes. The data ordering scheme by $w_{i}$ has surely ruined the relative within sample stability of $\hat{\eta}_{w}^{O L S}$ when data are ordered by wife's age. It should be noted that although full-sample parameter estimates are invariant to different data ordering schemes, their within-sample recursive processes are not unless there is no hidden dependence between randomly collected cross-section sample observations (see [43]).

10 This is in broad concord with separate treatments of extensive margins and intensive margins, e.g., see [41].

11 An economic rationale is offered by Eika, et al. [42]: assertive mating often results in correlation between non wife family income/husband's wage and wife's income. 
Table 6. OLS estimates of $\eta_{w}$ in model (1'), working wife samples ordered by $w_{i}$.

\begin{tabular}{|c|c|c|c|c|c|}
\hline & & \multicolumn{2}{|c|}{$\ln \left(I_{i}\right)$ Using Husband Wage Rate } & \multicolumn{2}{|c|}{$\ln \left(I_{i}\right)$ Using Non-wife Family Income } \\
\hline & & PSID & CPS & PSID & CPS \\
\hline \multirow{5}{*}{1980} & $\eta_{w}^{O L S}$ & 0.1054 & $0.0643^{* *}$ & 0.0915 & $0.0604^{* *}$ \\
\hline & 95\% C.I.^ & $(-0.0315,0.2423)$ & $(0.0105,0.1182)$ & $(-0.0439,0.2268)$ & $(0.0070,0.1139)$ \\
\hline & AR 1-2 & $23.360[0.0000]^{* *}$ & $804.89[0.0000]^{* *}$ & $105.97[0.0000] * *$ & $795.77[0.0000]^{* *}$ \\
\hline & Normal. & $1823.1[0.0000]^{* *}$ & $21,396[0.0000]^{* *}$ & $1810.0[0.0000]^{* *}$ & $21,253[0.0000]^{* *}$ \\
\hline & RESET & $8.8543[0.0001]^{* *}$ & $16.824[0.0000] * *$ & $6.3416[0.0018]^{* *}$ & $25.769[0.0000]^{* *}$ \\
\hline \multirow{5}{*}{1990} & $\eta_{w}^{O L S}$ & $0.1615^{* *}$ & $0.2235^{* *}$ & $0.1458^{* *}$ & $0.2218^{* *}$ \\
\hline & 95\% C.I.^ & $(0.0989,0.2240)$ & $(0.1843,0.2627)$ & $(0.0846,0.2071)$ & $(0.1825,0.2610)$ \\
\hline & AR 1-2 & $43.640[0.0000]^{* *}$ & $678.45[0.0000]^{* *}$ & $43.999[0.0000]^{* *}$ & $676.23[0.0000]^{* *}$ \\
\hline & Normal. & $3174.6[0.0000]^{* *}$ & $27,681[0.0000] * *$ & $3155.4[0.0000] * *$ & $27,353[0.0000]^{* *}$ \\
\hline & RESET & $9.5577[0.0001]^{* *}$ & $146.46[0.0000]^{* *}$ & $10.635[0.0000]^{* *}$ & $114.92[0.0000]$ ** \\
\hline \multirow{5}{*}{1999} & $\eta_{w}^{O L S}$ & $0.1305^{* *}$ & $0.0947^{* *}$ & $0.1219^{* *}$ & $0.0926^{* *}$ \\
\hline & 95\% C.I.^ & $(0.0546,0.2064)$ & $(0.0589,0.1304)$ & $(0.0459,0.1978)$ & $(0.0571,0.1280)$ \\
\hline & AR 1-2 & $7.2759[0.0007]^{* *}$ & $439.84[0.0000]^{* *}$ & $7.5549[0.0005]^{* *}$ & $441.26[0.0000]^{* *}$ \\
\hline & Normal. & $2872.1[0.0000]^{* *}$ & $29,232[0.0000]{ }^{* *}$ & $2796.9[0.0000]$ ** & $29,061[0.0000]^{* *}$ \\
\hline & RESET & $12.484[0.0000]^{* *}$ & $58.163[0.0000]$ ** & $10.310[0.0000]^{* *}$ & $38.031[0.0000]^{* *}$ \\
\hline \multirow{5}{*}{2003} & $\eta_{w}^{O L S}$ & -0.0193 & $0.0652^{* *}$ & -0.0233 & $0.0635^{* *}$ \\
\hline & 95\% C.I.^ & $(-0.0992,0.0606)$ & $(0.0383,0.0921)$ & $(-0.1015,0.0549)$ & $(0.0366,0.0904)$ \\
\hline & AR 1-2 & $26.462[0.0000]^{* *}$ & $958.81[0.0000]^{* *}$ & $27.154[0.0000] * *$ & $952.95[0.0000] * *$ \\
\hline & Normal. & $3806.7[0.0000]^{* *}$ & $51,467[0.0000] * *$ & $3771.7[0.0000] * *$ & $51,051[0.0000] * *$ \\
\hline & RESET & $4.7041[0.0092]^{* *}$ & $102.35[0.0000]^{* *}$ & $2.0922[0.1237]$ & $52.963[0.0000]$ ** \\
\hline \multirow{5}{*}{2007} & $\eta_{w}^{O L S}$ & $0.0811^{*}$ & 0.0832 ** & $0.0722 *$ & $0.0773^{* *}$ \\
\hline & 95\% C.I.^ & $(0.0135,0.1487)$ & $(0.0566,0.1097)$ & $(0.0066,0.1378)$ & $(0.0512,0.1035)$ \\
\hline & AR 1-2 & $39.750[0.0000]^{* *}$ & $773.51[0.0000]^{* *}$ & $41.538[0.0000]^{* *}$ & $780.35[0.0000]^{* *}$ \\
\hline & Normal. & $4043.5[0.0000]^{* *}$ & $48,555[0.0000]{ }^{* *}$ & $4000.9[0.0000]$ ** & $48,375[0.0000]^{* *}$ \\
\hline & RESET & $10.934[0.0000] * *$ & $132.26[0.0000]^{* *}$ & $7.4330[0.0006]^{* *}$ & $74.285[0.0000] * *$ \\
\hline \multirow{5}{*}{2011} & $\eta_{w}^{O L S}$ & $0.1440^{* *}$ & $0.0786^{* *}$ & $0.1460^{* *}$ & $0.0775^{* *}$ \\
\hline & 95\% C.I.^ & $(0.0657,0.2222)$ & $(0.0501,0.1071)$ & $(0.0658,0.2262)$ & $(0.0493,0.1056)$ \\
\hline & AR 1-2 & $11.143[0.0000]^{* *}$ & $882.49[0.0000]^{* *}$ & $11.196[0.0000]$ ** & $874.96[0.0000] * *$ \\
\hline & Normal. & $4465.0[0.0000]^{* *}$ & $44,067[0.0000] * *$ & $4348.3[0.0000] * *$ & $43,288[0.0000]^{* *}$ \\
\hline & RESET & $20.646[0.0000] * *$ & $56.446[0.0000] * *$ & $18.563[0.0000]$ ** & $59.066[0.0000] * *$ \\
\hline
\end{tabular}

C.I. stands for confidence interval; ^ stands for HCSE robust standard errors used; ** and * indicate significance at $1 \%$ and $5 \%$ respectively. AR 1-2 stands for 2 nd-order residual autocorrelation test; Normal. stands for residual normality test; RESET stands for Ramsey regression specification test.

Such hidden dependence can be revealed by appropriate data ordering choice, as shown by Qin and Liu [36]. Their choice is based on the observation that many economic variables are scale related and that it is frequently too simple to assume a linear/static model between such scale-dependent variables. This linearity assumption amounts to assuming local interdependence or no hidden dependence between observations from the viewpoint of joint probability distribution. Ordering data by the conditional scale-dependent variable of concern serves as an easy way to test this assumption. When the assumption is rejected, the revealed nonlinear effect can be captured by augmenting a static model into a difference-equation model, which captures the gradient of the nonlinear effect much more effectively than the use of conditional scale-dependent variables in a quadratic or cubic form. In the present case, the ordering scheme by wife's age or by family income largely conceals the hidden nonlinear scale effect by wage rates. This type of ordering schemes is described to as "regime mixing" by Zeileis and Hornik [34].

The data ordering effect is best illustrated by comparison of the 1999 OLS recursive estimates, under the ordering scheme by women's age, presented in Figure 1 with those of the same wave under the ordering scheme of women's wage presented in Figure 2. 
Table 7. Hansen parameter instability test statistics under different data ordering schemes for $\eta_{w}^{O L S}$ in the right two columns of Table 6.

\begin{tabular}{cccccccc}
\hline Data Source & Ordered by & $\mathbf{1 9 8 0}$ & $\mathbf{1 9 9 0}$ & $\mathbf{1 9 9 9}$ & $\mathbf{2 0 0 3}$ & $\mathbf{2 0 0 7}$ & $\mathbf{2 0 1 1}$ \\
\hline \multirow{3}{*}{ CPS } & Age & $1.4209^{* *}$ & $2.0299^{* *}$ & $1.5980^{* *}$ & $2.0369^{* *}$ & $1.8514^{* *}$ & $1.7945^{* *}$ \\
& Income & 0.35413 & $1.5616^{* *}$ & $1.0103^{* *}$ & $1.7882^{* *}$ & $1.1242^{* *}$ & $2.1583^{* *}$ \\
& Wage & $14.442^{* *}$ & $11.990^{* *}$ & $10.172^{* *}$ & $13.754^{* *}$ & $10.596^{* *}$ & $10.872^{* *}$ \\
\hline \multirow{2}{*}{ PSID } & Age & 0.051762 & 0.089821 & 0.093238 & 0.15852 & 0.16041 & 0.46426 \\
& Income & 0.22696 & 0.4553 & 0.26751 & 0.17328 & 0.35785 & 0.39903 \\
& Wage & $1.0210^{* *}$ & $1.5180^{* *}$ & $1.1481^{* *}$ & $1.4238^{* *}$ & $2.1837^{* *}$ & $1.8662^{* *}$ \\
\hline
\end{tabular}

${ }^{* *}$ and ${ }^{*}$ indicate significance at $1 \%$ and $5 \%$ respectively.
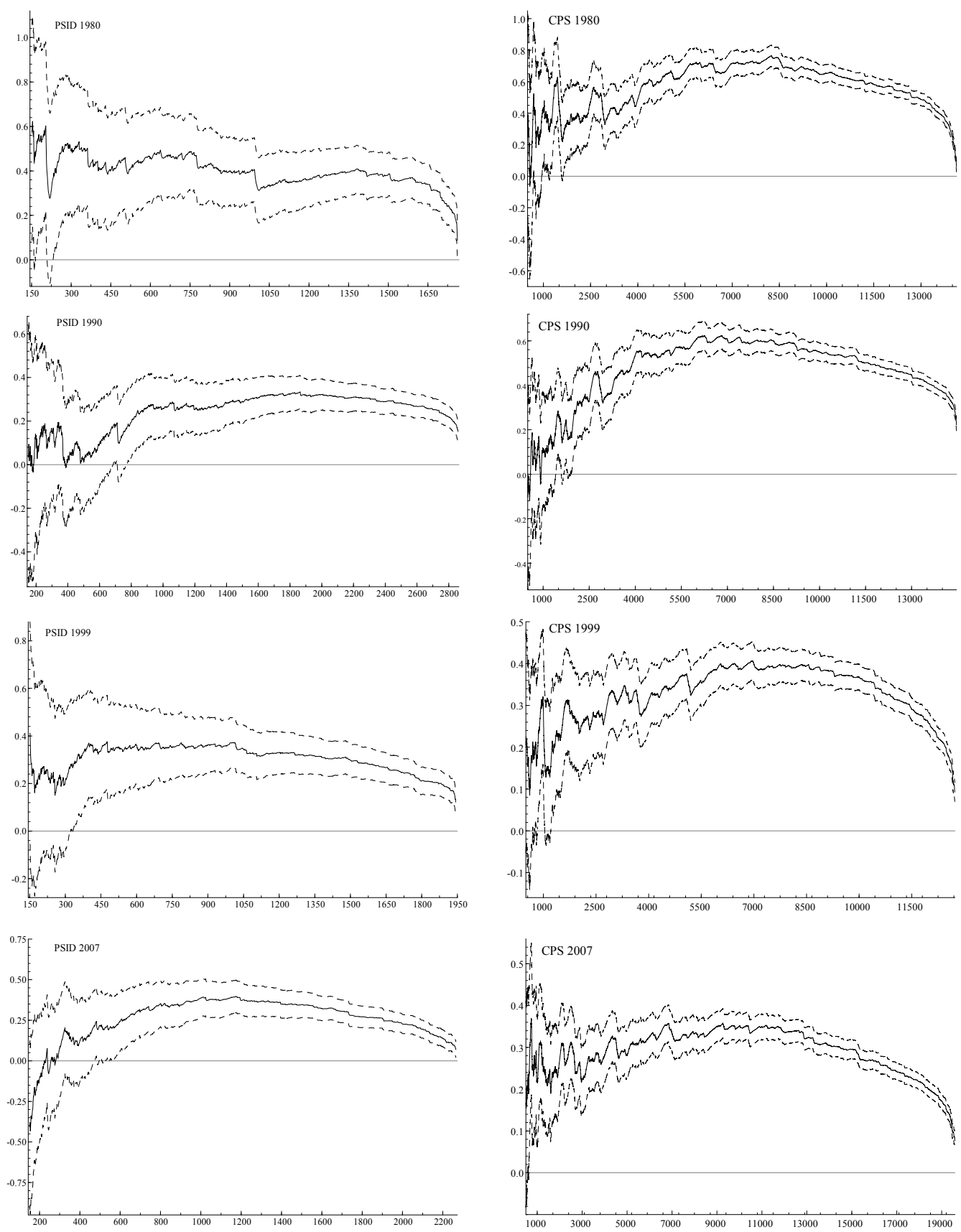

Figure 2. OLS recursive estimation of $\eta_{w}$ in Model $\left(1^{\prime}\right)$ when data are ordered by wage. 
A striking pattern emerges when we examine and compare the OLS recursive processes of different waves under the ordering scheme by $w_{i}$ in Figure 2 . The recursive elasticity estimates follow a somewhat smooth convex curve. Considering the recursive nature of increasing sample sizes, the curves tell us that elasticity of low wage rate earners differs significantly from that of high wage rate earners. This leads us to partition the sample into two parts. The partition wage values are chosen by two considerations. Statistically, they adequately represent the turning points of the convex curves; ${ }^{12}$ economically, they are comparable when converted into real-value terms by the US inflation rates. The key results of the partitioned regressions are reported in Table 8.

Table 8. OLS estimates of $\eta_{w}$ in model (1') and related statistics, working wife samples partitioned into two, data ordered by $w_{i}$.

\begin{tabular}{|c|c|c|c|c|}
\hline Data Source & PSID & CPS & PSID & CPS \\
\hline 1980 & \multicolumn{2}{|c|}{$<\$ 5$} & \multicolumn{2}{|c|}{$>\$ 5$} \\
\hline$\eta_{w}^{\mathrm{OLS}}$ & $0.4008^{* *}$ & $0.7523^{* *}$ & $-0.7344^{* *}$ & $-0.8744^{* *}$ \\
\hline 95\% C.I.^ & $(0.2354,0.5662)$ & $(0.6793,0.8254)$ & $(-1.1540,-0.3148)$ & $(-0.9706,-0.7784)$ \\
\hline Hansen & 0.097470 & $1.2795^{* *}$ & $0.79390 * *$ & $5.4997^{* *}$ \\
\hline AR 1-2 & $44.488[0.0000]^{* *}$ & $259.18[0.0000] * *$ & $42.455[0.0000]^{* *}$ & $232.38[0.0000]^{* *}$ \\
\hline Normal. & $598.05[0.0000]^{* *}$ & $9105.4[0.0000]^{* *}$ & $1260.2[0.0000]^{* *}$ & $7108.9[0.0000]^{* *}$ \\
\hline RESET & $4.0836[0.0171]^{*}$ & $18.388[0.0000]^{* *}$ & $22.236[0.0000]^{* *}$ & $112.47[0.0000]^{* *}$ \\
\hline 1990 & \multicolumn{2}{|c|}{$<\$ 8$} & \multicolumn{2}{|c|}{$>\$ 8$} \\
\hline$\eta_{w}^{O L S}$ & 0.2780 ** & $0.6017^{* *}$ & $-0.3489^{* *}$ & $-0.4034^{* *}$ \\
\hline 95\% C.I.^ & $(0.0912,0.2005)$ & $(0.5341,0.6693)$ & $(-0.4933,-0.2044)$ & $(-0.4818,-0.3251)$ \\
\hline Hansen & 0.24888 & $1.1302 * *$ & 0.43981 & $3.6915^{* *}$ \\
\hline AR 1-2 & $28.174[0.0000] * *$ & $203.75[0.0000]$ ** & $4.0878[0.0170]^{*}$ & $304.19[0.0000] * *$ \\
\hline Normal. & $1160.6[0.0000]^{* *}$ & $8186.1[0.0000]^{* *}$ & $1908.7[0.0000] * *$ & $16,933[0.0000]^{* *}$ \\
\hline RESET & $4.6074[0.0101]^{*}$ & $24.824[0.0000]^{* *}$ & $25.942[0.0000]^{* *}$ & $92.994[0.0000]^{* *}$ \\
\hline 1999 & \multicolumn{2}{|c|}{$<\$ 10$} & \multicolumn{2}{|c|}{$>\$ 10$} \\
\hline$\eta_{w}^{O L S}$ & 0.3601 ** & $0.3489^{* *}$ & $-0.1304^{*}$ & -0.3361 ** \\
\hline 95\% C.I.^ & $(0.1836,0.5366)$ & $(0.2824,0.4153)$ & $(-0.2557,-0.0050)$ & $(-0.4020,-0.2702)$ \\
\hline Hansen & 0.083408 & 0.39901 & 0.25306 & $2.1439^{* *}$ \\
\hline AR 1-2 & $3.2069[0.0410]^{*}$ & $114.53[0.0000]^{* *}$ & $1.6441[0.1936]$ & $214.87[0.0000]]^{* *}$ \\
\hline Normal. & $581.82[0.0000]$ ** & $7568.7[0.0000]^{* *}$ & $2086.3[0.0000]^{* *}$ & $15,967[0.0000] * *$ \\
\hline RESET & $1.0228[0.3601]$ & $21.939[0.0000]^{* *}$ & $5.4624[0.0044]^{* *}$ & $89.717[0.0000]^{* *}$ \\
\hline 2003 & \multicolumn{2}{|c|}{$<\$ 11$} & \multicolumn{2}{|c|}{$>\$ 11$} \\
\hline$\eta_{w}^{O L S}$ & $0.1976^{* *}$ & $0.3225^{* *}$ & $-0.4171^{* *}$ & $-0.2890 * *$ \\
\hline 95\% C.I.^ & $(0.0544,0.3408)$ & $(0.2687,0.3762)$ & $(-0.5696,-0.2646)$ & $(-0.3360,-0.2420)$ \\
\hline Hansen & 0.066383 & $1.1583 * *$ & 0.45268 & $3.4500 * *$ \\
\hline AR 1-2 & $4.2232[0.0150] *$ & $257.47[0.0000]^{* *}$ & $12.054[0.0000]^{* *}$ & $492.32[0.0000]^{* *}$ \\
\hline Normal. & $409.73[0.0000] * *$ & $9296.9[0.0000] * *$ & $3580.2[0.0000] * *$ & $36,000[0.0000]^{* *}$ \\
\hline RESET & $0.6505[0.5221]$ & $20.417[0.0000]^{* *}$ & $28.754[0.0000]^{* *}$ & $160.74[0.0000]^{* *}$ \\
\hline 2007 & \multicolumn{2}{|c|}{$<\$ 13$} & \multicolumn{2}{|c|}{$>\$ 13$} \\
\hline$\eta_{w}^{\mathcal{O L S}}$ & $0.3395^{* *}$ & 0.3299 ** & $-0.2396^{* *}$ & $-0.2367^{* *}$ \\
\hline 95\% C.I.^ & $(0.1855,0.4934)$ & $(0.2783,0.3814)$ & $(-0.3424,-0.1368)$ & $(-0.2841,-0.1894)$ \\
\hline Hansen & 0.45521 & $0.47376^{*}$ & 0.093207 & $1.2606^{* *}$ \\
\hline AR 1-2 & $15.908[0.0000]^{* *}$ & $238.84[0.0000]^{* *}$ & $9.4808[0.0001]^{* *}$ & $372.39[0.0000]^{* *}$ \\
\hline Normal. & $891.89[0.0000]^{* *}$ & $9769.9[0.0000]^{* *}$ & $2507.1[0.0000]^{* *}$ & $34,758[0.0000]^{* *}$ \\
\hline RESET & $2.1334[0.1191]$ & $22.140[0.0000]^{* *}$ & $7.1945[0.0008]^{* *}$ & $77.495[0.0000]^{* *}$ \\
\hline 2011 & \multicolumn{2}{|c|}{$<\$ 13.50$} & \multicolumn{2}{|c|}{$>\$ 13.50$} \\
\hline$\eta_{w}^{O L S}$ & $0.3278^{* *}$ & $0.3330 * *$ & $-0.2057^{* *}$ & $-0.2517 * *$ \\
\hline 95\% C.I.^ & $(0.1452,0.5105)$ & $(0.2756,0.3904)$ & $(-0.3452,-0.0663)$ & $(-0.3015,-0.2019)$ \\
\hline Hansen & 0.16577 & $1.1026^{* *}$ & 0.35168 & $-10.1^{* *}$ \\
\hline AR 1-2 & $6.4511[0.0017] * *$ & $241.38[0.0000]$ ** & $0.2538[0.7759]$ & $445.02[0.0000] * *$ \\
\hline Normal. & $803.83[0.0000] * *$ & $7703.4[0.0000]^{* *}$ & $3244.4[0.0000] * *$ & $31,573[0.0000]^{* *}$ \\
\hline RESET & $0.6919[0.5009]$ & $22.142[0.0000] * *$ & $32.758[0.0000]^{* *}$ & $120.92[0.0000]^{* *}$ \\
\hline
\end{tabular}

C.I. stands for confidence interval; $\wedge$ stands for HCSE robust standard errors used; * and ${ }^{* *}$ indicate significant at $5 \%$ and $1 \%$ respectively; Wage partition values are real-value comparable after deflated by the US inflation rates; AR 1-2 stands for 2nd-order residual autocorrelation test; Normal.: stands for residual normality test; RESET stands for Ramsey regression specification test.

Four features are immediately noticeable from this table as compared to the previous estimation results summarised in Tables 6 and 7. First, there is little statistical difference between the elasticity

12 The location of the turning point has been identified with the help of recursive break point Chow test. 
estimates of the two data sources for most of the waves. Secondly, the elasticity estimates of the lower part are significantly positive whereas those of the upper part are significantly negative. Thirdly, there are signs of reducing severity of the diagnostic test rejections, mainly from the PSID source. Fourthly, parameter instability is still largely present, especially for estimates using the CPS source, as shown by the Hansen test statistics. Inspection of recursive estimation results tells us that the instability mostly occurs at the tail ends of the wage distribution. Therefore, we further partition the two subsamples to cut out the tail ends, aiming to search for the comparable wage rate ranges within which the elasticity estimates remain statistically constant. The search yields a comparable wage range of $\$ 4-\$ 10$ from the lower end and \$10-\$22 from the upper end at the 1999 price level. We refer to these two partition ranges as the lower mid group and the upper mid group in Table 9, where the main results of this search are summarised.

Two key changes are discernible from Table 8 to Table 9. The elasticity estimates of the upper mid group are statistically insignificant from zero, and all the estimates in the lower mid group have passed the Hansen stability test whereas only two have failed the test in the upper mid group. Figure 3 plots all the OLS recursive graphs of the lower mid group. The degree of parameter stability is quite impressive, especially considering the large sample sizes of the CPS source. However, what is even more impressive is the closeness of these elasticity estimates—roughly around 0.4-not only between the two data sources of the same wave but also across different waves, especially the last four waves.

Table 9. OLS estimates of $\eta_{w}$ in model (1') and related statistics, working wife samples partitioned into lower mid and upper mid groups, plus RAL estimates for autocorrelated residual correction of the lower mid group, data ordered by $w_{i}$.

\begin{tabular}{|c|c|c|c|c|c|c|}
\hline & \multicolumn{4}{|c|}{ Lower Mid Group } & \multicolumn{2}{|c|}{ Upper Mid Group } \\
\hline & \multicolumn{2}{|c|}{ PSID } & \multicolumn{2}{|c|}{ CPS } & PSID & CPS \\
\hline & OLS & RAL & OLS & RAL & OLS & OLS \\
\hline 1980 & \multicolumn{4}{|c|}{$\$ 2.00-\$ 5.00$} & \multicolumn{2}{|c|}{$\$ 5.00-\$ 10.50$} \\
\hline$\eta_{w}^{O L S}$ & 0.3297 * & 0.2924 & $0.9236^{* *}$ & $0.9312^{* *}$ & 0.2681 & -0.1175 \\
\hline 95\% C.I.^ & $(0.03,0.63)$ & $(-0.07,0.65)$ & $(0.83,1.02)$ & $(0.82,1.05)$ & $(-0.09,0.63)$ & $(-0.26,0.03)$ \\
\hline Hansen & 0.066046 & & 0.25999 & & 0.38964 & $1.1773^{* *}$ \\
\hline AR 1-2 & $35.5[0.00]$ & & $237.8[0.00]$ & & $44.64[0.00]$ & 200.80 [0.00] \\
\hline Normal. & $661[0.00]$ & $749[0.00]$ & 9667 [0.00] & $8366[0.00]$ & $1074[0.00]$ & $10,157[0.00]$ \\
\hline RESET & $3.73[0.02]$ & & $10.59[0.00]$ & & $3.848[0.02]$ & $7.1779[0.00]$ \\
\hline 1990 & \multicolumn{4}{|c|}{$\$ 3.00-\$ 8.00$} & \multicolumn{2}{|c|}{$\$ 8.00-\$ 17.00$} \\
\hline$\eta_{w}^{O L S}$ & $0.4124^{* *}$ & $0.4075^{* *}$ & $0.7719^{* *}$ & $0.7718^{* *}$ & -0.0755 & 0.0375 \\
\hline 95\% C.I.^ & $(0.25,0.58)$ & $(0.21,0.61)$ & $(0.69,0.86)$ & $(0.67,0.88)$ & $(-0.25,0.10)$ & $(-0.06,0.13)$ \\
\hline Hansen & 0.063294 & & 0.36629 & & 0.024241 & 0.15996 \\
\hline AR 1-2 & $37.54[0.00]$ & & $170.1[0.00]$ & & $9.350[0.00]$ & $224.4[0.00]$ \\
\hline Normal. & 1207 [0.00] & $1292[0.00]$ & 8698 [0.00] & $7629[0.00]$ & $1675[0.00]$ & $17,938[0.00]$ \\
\hline RESET & $5.577[0.00]$ & & $17.76[0.00]$ & & $5.657[0.00]$ & $15.07[0.00]$ \\
\hline 1999 & \multicolumn{4}{|c|}{$\$ 4.00-\$ 10.00$} & \multicolumn{2}{|c|}{$\$ 10.00-\$ 22.00$} \\
\hline$\eta_{w}^{O L S}$ & $0.5095^{* *}$ & $0.5098^{* *}$ & $0.3916^{\text {** }}$ & $0.3936^{* *}$ & 0.1129 & 0.0668 \\
\hline 95\% C.I.^ & $(0.26,0.76)$ & $(0.25,0.77)$ & $(0.29,0.49)$ & $(0.28,0.51)$ & $(-0.05,0.28)$ & $(-0.02,0.15)$ \\
\hline Hansen & 0.069269 & & 0.30388 & & 0.067335 & 0.66744 * \\
\hline AR 1-2 & $3.15[0.04]$ & & $95.10[0.00]$ & & 1.119 [0.33] & $174.3[0.00]$ \\
\hline Normal. & $692.8[0.00]$ & $674.6[0.00]$ & 8097 [0.00] & $7523[0.00]$ & $1769.5[0.00]$ & $16,403[0.00]$ \\
\hline RESET & $2.363[0.10]$ & & $20.59[0.00]$ & & $12.55[0.00]$ & $13.450[0.00]$ \\
\hline
\end{tabular}


Table 9. Cont.

\begin{tabular}{|c|c|c|c|c|c|c|}
\hline & \multicolumn{4}{|c|}{ Lower Mid Group } & \multicolumn{2}{|c|}{ Upper Mid Group } \\
\hline & \multicolumn{2}{|c|}{ PSID } & \multicolumn{2}{|c|}{ CPS } & \multirow{2}{*}{$\begin{array}{c}\text { PSID } \\
\text { OLS }\end{array}$} & \multirow{2}{*}{$\begin{array}{l}\text { CPS } \\
\text { OLS }\end{array}$} \\
\hline & OLS & RAL & OLS & RAL & & \\
\hline 2003 & \multicolumn{4}{|c|}{$\$ 4.50-\$ 11.00$} & \multicolumn{2}{|c|}{$\$ 11.00-\$ 24.00$} \\
\hline$\eta_{w}^{O L S}$ & 0.2071 & & $0.4530^{* *}$ & 0.4542 ** & -0.0142 & 0.0248 \\
\hline 95\% C.I.^ & $\begin{array}{c}(-0.02, \\
0.44)\end{array}$ & & $(0.37,0.54)$ & $(0.35,0.56)$ & $(-0.17,0.14)$ & $(-0.04,0.09)$ \\
\hline Hansen & 0.051773 & & 0.29838 & & 0.095798 & 0.33216 \\
\hline AR 1-2 & $2.787[0.06]$ & & $255.3[0.00]$ & & $6.5423[0.00]$ & 297.37 [0.00] \\
\hline Normal. & $328.0[0.00]$ & & $\begin{array}{l}10,014 \\
{[0.00]}\end{array}$ & 8559 [0.00] & $2418.1[0.00]$ & $31,624[0.00]$ \\
\hline RESET & $2.079[0.13]$ & & $22.15[0.00]$ & & $1.3935[0.25]$ & $32.201[0.00]$ \\
\hline 2007 & \multicolumn{4}{|c|}{$\$ 5.00-\$ 13.00$} & \multicolumn{2}{|c|}{$\$ 13.00-\$ 27.00$} \\
\hline$\eta_{w}^{O L S}$ & $0.6299 * *$ & $0.6347^{* *}$ & $0.4295^{* *}$ & $0.424609 * *$ & -0.1118 & -0.0239 \\
\hline 95\% C.I.^ & $(0.36,0.90)$ & $(0.31,0.96)$ & $(0.36,0.50)$ & $(0.34,0.51)$ & $(-0.28,0.05)$ & $(-0.09,0.04)$ \\
\hline Hansen & 0.046116 & \multirow{4}{*}{$899.7[0.00]$} & 0.26206 & \multirow{4}{*}{$9526[0.00]$} & 0.063481 & 0.28024 \\
\hline AR 1-2 & $18.53[0.00]$ & & $\begin{array}{l}229.09 \\
{[0.00]}\end{array}$ & & $19.088[0.00]$ & $311.17[0.00]$ \\
\hline Normal. & 889.4 [0.00] & & $\begin{array}{l}10,816 \\
{[0.00]}\end{array}$ & & $2012.6[0.00]$ & $28,177[0.00]$ \\
\hline RESET & $1.597[0.20]$ & & $\begin{array}{l}34.515 \\
{[0.00]}\end{array}$ & & $10.836[0.00]$ & 7.1955 [0.00] \\
\hline 2011 & \multicolumn{4}{|c|}{$\$ 5.50-\$ 13.50$} & \multicolumn{2}{|c|}{$\$ 13.50-\$ 29.50$} \\
\hline$\eta_{w}^{O L S}$ & $0.4793^{* *}$ & $0.4859 * *$ & $0.4349^{* *}$ & $0.4323^{* *}$ & 0.0901398 & 0.0053 \\
\hline 95\% C.I.^ & $(0.18,0.78)$ & $(0.18,0.80)$ & $(0.35,0.53)$ & $(0.32,0.55)$ & $(-0.07,0.25)$ & $(-0.06,0.07)$ \\
\hline Hansen & 0.13927 & \multirow{3}{*}{$806.7[0.00]$} & 0.30747 & \multirow{3}{*}{$7364[0.00]$} & 0.020069 & 0.36278 \\
\hline AR 1-2 & $6.497[0.00]$ & & $\begin{array}{l}224.95 \\
{[0.00]}\end{array}$ & & $0.9746[0.38]$ & $234.79[0.00]$ \\
\hline Normal. & $920.9[0.00]$ & & $\begin{array}{l}8782.1 \\
{[0.00]}\end{array}$ & & $2407.3[0.00]$ & $22,546[0.00]$ \\
\hline RESET & $1.180[0.31]$ & & $\begin{array}{l}18.097 \\
{[0.00]}\end{array}$ & & $1.5094[0.22]$ & $24.795[0.00]$ \\
\hline
\end{tabular}

RAL is the $\mathrm{r}^{\text {th }}$-order autoregressive least-squares method; C.I. stands for confidence interval; ${ }^{\wedge}$ stands for HCSE robust standard errors used; * and ${ }^{* *}$ indicate significant at $5 \%$ level and $1 \%$ respectively; Wage partition values are real-value comparable after deflated by the US inflation rates; AR 1-2 stands for 2nd-order residual autocorrelation test; Normal. stands for residual normality test; RESET stands for Ramsey regression specification test.

Since the lower mid group stands out as having the most stable and significantly positive wage elasticity estimates, we try to further investigate the robustness of this finding from two aspects. First, we run the reverse regression model, namely the upper equation in (4) with data ordered by $H_{i}$ and try the same sample partition search to see if it is possible to find ranges of work hours in which relatively invariant parameter estimates of $\gamma_{1}$ exist. This experiment can be seen as a crosscheck of whether $w_{i}$ satisfies data ordering condition (a). The search yields no positive results, as shown in Table 10. The universal lack of parameter stability and the statistical similarity between the two data sources across different waves serve as strong evidence against postulating $H_{i}$ as a conditional variable for $w_{i}$. 

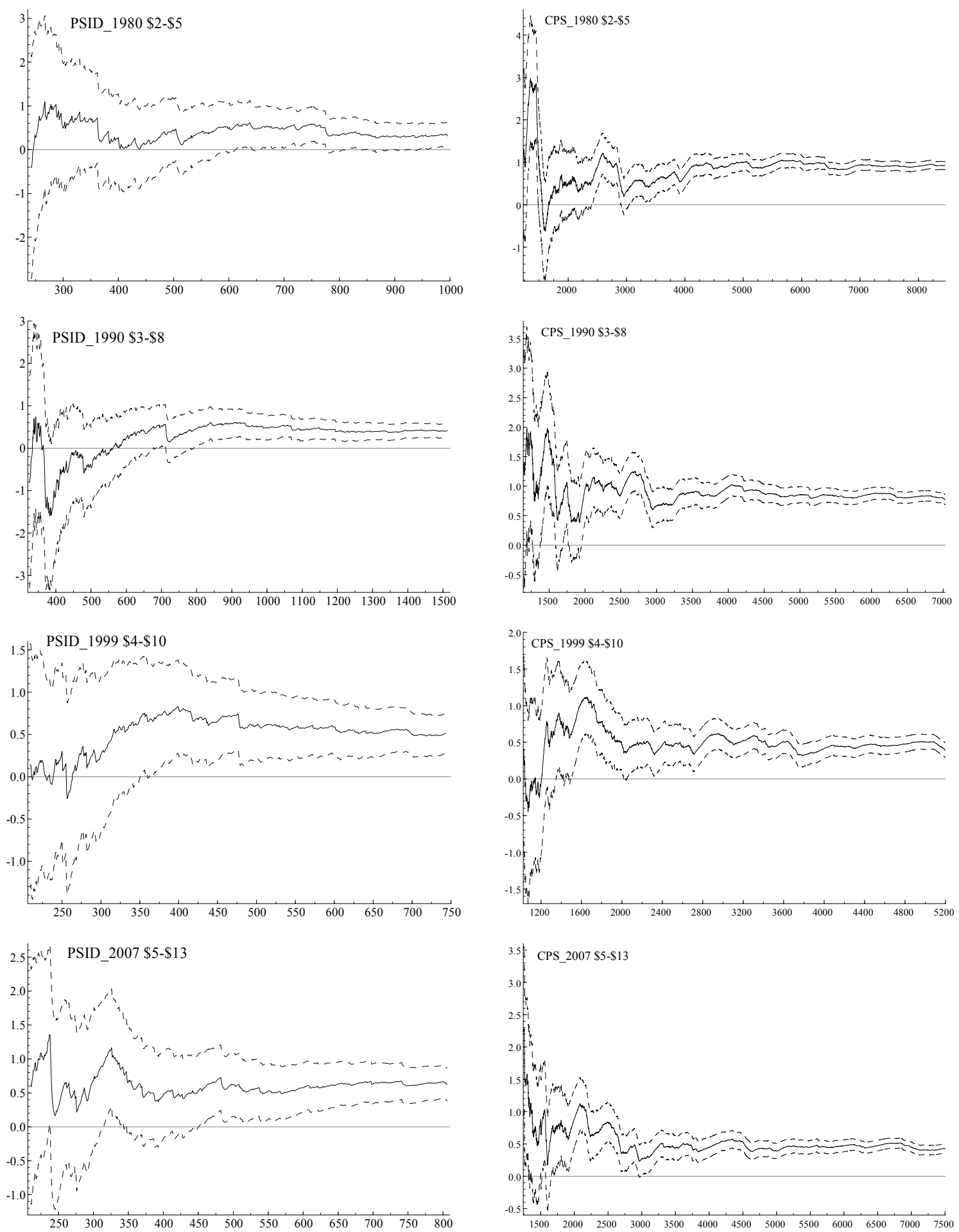

Figure 3. Recursive estimation of $\eta_{w}$ for the lower mid group, data ordered by wage. 
Table 10. OLS estimates of $\gamma_{1}$ in the lower equation of (4) and related statistics, full working wife samples and subsamples in various partitions, data ordered by $H_{i}$.

\begin{tabular}{|c|c|c|c|c|c|c|c|}
\hline & & 1980 & 1990 & 1999 & 2003 & 2007 & 2011 \\
\hline \multicolumn{8}{|c|}{ Full sample } \\
\hline \multirow{3}{*}{ PSID } & $\gamma_{1}^{O L S}$ & $0.00008^{* *}$ & $0.00008^{* *}$ & 0.000064 * & -0.000008 & 0.000035 & $0.00007^{* *}$ \\
\hline & $p$-value of $t$-test $t^{\wedge}$ & 0.0003 & 0.0000 & 0.0122 & 0.6356 & 0.1174 & 0.0054 \\
\hline & Hansen test & 0.5524 * & $1.5082^{* *}$ & $1.1711 * *$ & $0.5951 *$ & $0.5064 *$ & $1.6662 * *$ \\
\hline \multirow{3}{*}{ CPS } & $\gamma_{1}^{O L S}$ & $0.00006^{* *}$ & $0.00012^{* *}$ & $0.00008^{* *}$ & $0.00006^{* *}$ & $0.00007^{* *}$ & $0.00008^{* *}$ \\
\hline & $p$-value of $t$-test ${ }^{\wedge}$ & 0.0000 & 0.0000 & 0.0000 & 0.0000 & 0.0000 & 0.0000 \\
\hline & Hansen test & $59.27^{* *}$ & $55.4^{* *}$ & $61.4^{* *}$ & $98.3^{* *}$ & $103.1^{* *}$ & $94.53 * *$ \\
\hline \multicolumn{8}{|c|}{ Part-timers } \\
\hline \multicolumn{8}{|c|}{ 1-1680 h per year } \\
\hline \multirow{3}{*}{ PSID } & $\gamma_{1}^{O L S}$ & $0.000095^{*}$ & $0.00011^{* *}$ & $0.00016^{* *}$ & 0.000001 & 0.000098 & $0.00019^{* *}$ \\
\hline & $p$-value of $t$-test $t^{\wedge}$ & 0.0284 & 0.0029 & 0.0077 & 0.9788 & 0.0617 & 0.0005 \\
\hline & Hansen test & 0.0947 & 0.2481 & 0.0262 & 0.9170 * & 0.1231 & 0.0837 \\
\hline \multirow{3}{*}{ CPS } & $\gamma_{1}^{O L S}$ & -0.0001 ** & $0.00008^{* *}$ & -0.000032 & -0.000006 & 0.000018 & -0.000004 \\
\hline & $p$-value of $t$-test $t^{\wedge}$ & 0.0020 & 0.0000 & 0.1704 & 0.7252 & 0.3949 & 0.8688 \\
\hline & Hansen test & $2.36^{* *}$ & $1.01^{* *}$ & $1.82 * *$ & $4.33^{* *}$ & $4.23^{* *}$ & $3.29 * *$ \\
\hline \multicolumn{8}{|c|}{ 1-1000 h per year } \\
\hline \multirow{3}{*}{ PSID } & $\gamma_{1}^{O L S}$ & 0.000006 & -0.000016 & 0.00027 & $-0.0005^{* *}$ & 0.000097 & 0.00015 \\
\hline & $p$-value of $t$-test $t^{\wedge}$ & 0.9573 & 0.8694 & 0.1122 & 0.0018 & 0.4870 & 0.3376 \\
\hline & Hansen test & 0.3851 & 0.1088 & 0.0807 & 0.1591 & 0.0893 & 0.1349 \\
\hline \multirow{3}{*}{ CPS } & $\gamma_{1}^{O L S}$ & $-0.0002^{* *}$ & 0.000021 & $-0.0002^{* *}$ & $-0.0002^{* *}$ & $-0.0002^{* *}$ & -0.000266 \\
\hline & $p$-value of $t$-test ${ }^{\wedge}$ & 0.0000 & 0.6316 & 0.0028 & 0.0000 & 0.0007 & 0.0000 \\
\hline & Hansen test & $0.91^{* *}$ & 0.27 & $0.62 *$ & $2.28 * *$ & $1.19^{* *}$ & $1.58^{* *}$ \\
\hline \multicolumn{8}{|c|}{$1000-1680 \mathrm{~h}$ per year } \\
\hline \multirow{3}{*}{ PSID } & $\gamma_{1}^{O L S}$ & -0.00007 & $0.00028^{*}$ & 0.000126 & $0.00046^{* *}$ & $0.00037^{* *}$ & 0.00024 \\
\hline & $p$-value of $t$-test $t^{\wedge}$ & 0.5874 & 0.0178 & 0.3496 & 0.0039 & 0.0081 & 0.0699 \\
\hline & Hansen test & 0.0319 & 0.0931 & 0.0263 & 0.0824 & 0.1016 & 0.0721 \\
\hline \multirow{3}{*}{ CPS } & $\gamma_{1}^{O L S}$ & 0.000052 & 0.000038 & $0.00021^{* *}$ & -0.000004 & 0.000088 & -0.000025 \\
\hline & $p$-value of $t$-test $t^{\wedge}$ & 0.1747 & 0.4114 & 0.0001 & 0.9199 & 0.0575 & 0.5846 \\
\hline & Hansen test & $1.80 * *$ & $2.26 * *$ & $2.03 * *$ & $4.80 * *$ & $3.76^{* *}$ & $3.16^{* *}$ \\
\hline \multicolumn{8}{|c|}{ Full-timers } \\
\hline \multicolumn{8}{|c|}{$>1680 \mathrm{~h}$ per year ( $35 \mathrm{~h}$ per week) } \\
\hline \multirow{3}{*}{ PSID } & $\gamma_{1}^{O L S}$ & $-0.0002^{* *}$ & $-0.0002^{* *}$ & $-0.0001^{* *}$ & $-0.0002^{* *}$ & -0.00007 & $-0.0002^{* *}$ \\
\hline & $p$-value of $t$-test $t^{\wedge}$ & 0.0045 & 0.0000 & 0.0070 & 0.0000 & 0.1505 & 0.0000 \\
\hline & Hansen test & 0.1520 & 0.2044 & 0.1392 & 0.3486 & 0.0923 & 0.2045 \\
\hline \multirow{3}{*}{ CPS } & $\gamma_{1}^{O L S}$ & -0.000041 & -0.000032 & -0.000020 & $-0.0001^{* *}$ & $-0.0001^{* *}$ & $-0.0001^{* *}$ \\
\hline & $p$-value of $t$-test $t^{\wedge}$ & 0.1400 & 0.2088 & 0.4203 & 0.0004 & 0.0076 & 0.0041 \\
\hline & Hansen test & $124.1 * *$ & $132.2 * *$ & $107.0^{* *}$ & $185.5^{* *}$ & 190.0 ** & $174.4 * *$ \\
\hline \multicolumn{8}{|c|}{$1680-2400 \mathrm{~h}$ per year $(35-50 \mathrm{~h}$ per week) } \\
\hline \multirow{3}{*}{ PSID } & $\gamma_{1}^{O L S}$ & -0.00006 & -0.0001 & $-0.0003^{* *}$ & -0.00032 & -0.000054 & -0.00021 \\
\hline & $p$-value of $t$-test ${ }^{\wedge}$ & 0.5663 & 0.2303 & 0.0016 & 0.7047 & 0.5250 & 0.0512 \\
\hline & Hansen test & 0.2151 & 0.2549 & 0.1329 & 0.2457 & 0.1830 & 0.2289 \\
\hline \multirow{3}{*}{ CPS } & $\gamma_{1}^{O L S}$ & $0.00026^{* *}$ & $0.00031^{* *}$ & $0.00035^{* *}$ & $0.00021^{* *}$ & $0.00035^{* *}$ & $0.00028^{* *}$ \\
\hline & $p$-value of $t$-test ${ }^{\wedge}$ & 0.0000 & 0.0000 & 0.0000 & 0.0000 & 0.0000 & 0.0000 \\
\hline & Hansen test & $132.1^{* *}$ & $151.7^{* *}$ & $144.4^{* *}$ & $261.1^{* *}$ & $264.0 * *$ & $248.5^{* *}$ \\
\hline
\end{tabular}

$p$-value is the probability of the test statistics; ${ }^{\wedge}$ stands for HCSE robust standard errors used; ${ }^{*}$ and ${ }^{* *}$ indicate significant at $5 \%$ and $1 \%$ respectively.

The second aspect is to tackle the residual autocorrelation problem, which is widely observed from the diagnostic tests shown in Table 9. The autocorrelation actually indicates the presence of hidden dependence or nonlinear scale effect, as discussed above. Here, we re-estimate the model using the Cochrane-Orcutt autoregressive least-squares method for those instances where the OLS regression fails the residual AR test. Interestingly, the resulting elasticity estimates do not differ statistically from the OLS estimates, as shown in Table 9. This finding indicates that the nonlinear effect by data ordering satisfies the common factor restriction, e.g., see [44] (Chapter 7). In other words, the "short-run" wage effect is identical to the "long-run" wage effect. This is not very 
surprising considering that the "short-run" of the present case is the wage rate incremental (see [36] for more discussion on this point).

The discovery of constant elasticity estimates in two sub-groups of working wives leads us to another experiment of the IV route to see how invariant the two sub-group IV estimates are, using un-ordered subsample data. ${ }^{13}$ Table 11 summarises the results.

Table 11. IV estimates of $\alpha_{1}$ in model (2) and related statistics, for two wage rate sub-samples.

\begin{tabular}{|c|c|c|c|c|c|c|c|c|c|}
\hline \multirow{2}{*}{\multicolumn{2}{|c|}{ IVs }} & \multicolumn{4}{|c|}{ Set 1} & \multicolumn{4}{|c|}{ Set 3} \\
\hline & & CPS & PSID & CPS & PSID & CPS & PSID & CPS & PSID \\
\hline \multicolumn{2}{|c|}{ Wage Group } & \multicolumn{2}{|c|}{ Lower Mid } & \multicolumn{2}{|c|}{ Upper Mid } & \multicolumn{2}{|c|}{ Lower Mid } & \multicolumn{2}{|c|}{ Upper Mid } \\
\hline \multirow{4}{*}{1980} & $\alpha_{1}^{I V}$ & -51.826 & -3518.1 & 1411. ** & -49.47 & -135.85 & -3510.9 & $1612^{* *}$ & -18.54 \\
\hline & R.S.E. & 263.85 & 1897 & 276.376 & 445.18 & 261.266 & 1895.5 & 280.43 & 445.87 \\
\hline & Hausman & $9.392 * *$ & $11.26^{* *}$ & $29.63^{* *}$ & 0.1549 & $11.95^{* *}$ & $11.23^{* *}$ & $39.85^{* *}$ & 1.0 \\
\hline & Over-id. & $71.77^{* *}$ & 8.2155 & $48.15^{* *}$ & 4.7803 & $75.12 * *$ & 8.2446 & $67.98^{\text {** }}$ & 7.28 \\
\hline \multirow{4}{*}{1990} & $\alpha_{1}^{I V}$ & $-652.9 *$ & $-1568^{*}$ & $1137^{* *}$ & -44.698 & -513.47 & $-1487^{*}$ & $1180^{* *}$ & -78.07 \\
\hline & R.S.E. & 311.703 & 741.98 & 153.698 & 319.83 & 300.071 & 728.6 & 154.725 & 318.1 \\
\hline & Hausman & $20.53^{* *}$ & $12.35^{* *}$ & $57.65 * *$ & 0.0459 & $16.75^{* *}$ & $11.42 * *$ & $63.33^{* *}$ & 0.119 \\
\hline & Over-id. & $30.39 * *$ & $8.145^{* *}$ & 25.67 ** & $22.06^{* *}$ & $38.72 * *$ & 10.83 & $34.8^{* *}$ & $22.27^{* *}$ \\
\hline \multirow{4}{*}{1999} & $\alpha_{1}^{I V}$ & $-2082^{* *}$ & 424.863 & $920.9^{* *}$ & -547.64 & $-1991^{* *}$ & 498.2 & $964.2^{* *}$ & -444.88 \\
\hline & R.S.E. & 496.4 & 526.58 & 148.82 & 510.58 & 477.99 & 520.5 & 151.09 & 496.87 \\
\hline & Hausman & $43.62 * *$ & 0.0001 & $35.03 * *$ & 2.255 & $41.65^{* *}$ & 0.019 & $39.41 * *$ & 1.686 \\
\hline & Over-id. & $14.92^{* *}$ & $22.7^{* *}$ & $46.44^{* *}$ & $14.61^{* *}$ & 16.60 ** & $26.85^{* *}$ & $54.46^{* *}$ & $16.19^{* *}$ \\
\hline \multirow{4}{*}{2003} & $\alpha_{1}^{I V}$ & -1309 ** & -842.97 & 682.3 ** & 848.2 & $-1247^{* *}$ & -1121.4 & $672.3^{* *}$ & 852.76 \\
\hline & R.S.E. & 439.18 & 1511.2 & 122.444 & 443.1 & 433.67 & 1485.6 & 121.76 & 443.5 \\
\hline & Hausman & $19.03^{* *}$ & 0.69 & $29.88^{* *}$ & $4.9396^{*}$ & $17.78^{* *}$ & 1.171 & $28.97^{* *}$ & 4.994 * \\
\hline & Over-id. & $55.33 * *$ & $17.27^{* *}$ & 84.51 ** & 5.71 & $59.52 * *$ & $16.52^{* *}$ & $89.27^{* *}$ & 6.82 \\
\hline \multirow{4}{*}{2007} & $\alpha_{1}^{I V}$ & $-930^{* *}$ & 787.93 & 1122 ** & -418.53 & $-814^{* *}$ & 828.88 & $1121^{* *}$ & -418.12 \\
\hline & R.S.E. & 254.88 & 764.98 & 138.28 & 499.7 & 247.91 & 758.93 & 137.83 & 497.5 \\
\hline & Hausman & $33.05^{* *}$ & 0.10 & $72.52 * *$ & 0.35 & $28.18^{* *}$ & 0.1456 & $72.44^{* *}$ & 0.35 \\
\hline & Over-id. & $38.37^{* *}$ & 8.99 & $65.57^{* *}$ & 19.12 ** & $48.75^{* *}$ & 9.12 & $65.66^{* *}$ & 19.12 ** \\
\hline \multirow{4}{*}{2011} & $\alpha_{1}^{I V}$ & $-918.3^{*}$ & $1916.6^{*}$ & $1238^{* *}$ & $919.28^{*}$ & -517.98 & 1910 * & $1226^{* *}$ & $932.83 *$ \\
\hline & R.S.E. & 371.07 & 958.3 & 130.33 & 449.2 & 342.82 & 975.17 & 128.88 & 450.38 \\
\hline & Hausman & $13.54^{* *}$ & 2.42 & $103.9^{* *}$ & $4.442 *$ & 7.22 ** & 2.40 & $102.3^{* *}$ & $4.58 *$ \\
\hline & Over-id. & $19.73^{* *}$ & 3.29 & $92.39 * *$ & $11.67^{*}$ & $37.53^{* *}$ & 3.32 & $94.6 * *$ & $13.56^{*}$ \\
\hline
\end{tabular}

R.S.E. stands for robust standard errors; Hausman is the Wu-Hausman test of endogeneity; Over-id. stands for Sargan over-identification tests; ** and * indicate significance at $1 \%$ and $5 \%$ respectively; IV sets are described in Table 1. Wage rate groups are described in Table 9.

It is striking to see from the table that all the CPS data-based IV estimates for the lower mid wage group are now negative whereas the estimates for the upper mid wage group are several times larger than the full-sample estimates as compared to Table 1 . This result is contrary to the expectation that the elasticity of lower wage earners should be positive and larger than that of the higher wage earners. Unsurprisingly, all the IV test results remain unchanged from the full-sample results for the CPS data sets, with the Sargan test rejecting the validity of all the IV sets. The IV test results using the PSID data sets vary somewhat from those reported in Table 1. Interestingly, some test results alter between wage groups for the same IV sets, e.g., endogeneity is rejected in the upper wage group but not the lower wage group in 1980, and vice versa in 2003. These cases show us again how unreliable IV-generated wage variables can be when used as conditional variables. The degree of variedness in those sub-group IV estimates using the PSID data sets is not beyond expectation. On the whole, the cross-sample time-invariant feature revealed by the OLS estimates is absent here.

13 It should be noted that although the sub-group OLS experiment is based on the full-log model (1'), we have tried it on the semi-log model (1) and the constancy property remains virtually unchanged. 
The above findings not only reconfirm our rejection of models (2) and (4), but also carry a great deal of practical significance, at least from the following five aspects.

The first and obvious implication of our findings is that wage elasticity for the working wives is not a single-valued parameter. The evidence from Table 9 that statistically constant elasticities exist only with respect to certain wage groups undermines the premise of the labour supply wage effect as a single parameter using micro data. Consequently, a theoretical re-orientation is probably needed for those investigations which are aimed at establishing links between macro and micro labour supply elasticities. These findings also support more heterodox theories of labour market segmentation, e.g., $[45,46]$, and show potential avenues for future empirical research in this field.

Secondly, there is little evidence of shrinking wage elasticities from 1980 to 2011 as far as those statistically constant elasticities are concerned. On the contrary, these estimates have remained remarkably invariant, as shown in Table 9. Although some sign of decreasing elasticities is discernible from the CPS-based estimates of the three waves of 1980, 1990 and 1999, the decrease is statistically too weak to support the claim of shrinking elasticities. If we look at the aggregate estimates from Tables 1-6 differences in the wage elasticity estimates are somewhat more noticeable from these three waves. In order to find explanations to this phenomenon, we look into the share compositions of working wives by our sample partitions. What we find is a significant decline in the shares of the lower mid group combined with a significant increase in the shares of the upper mid group as well as the upper part from 1980 to 1999, whereas the shares have largely stabilised since 1999, as shown from Figure 4.
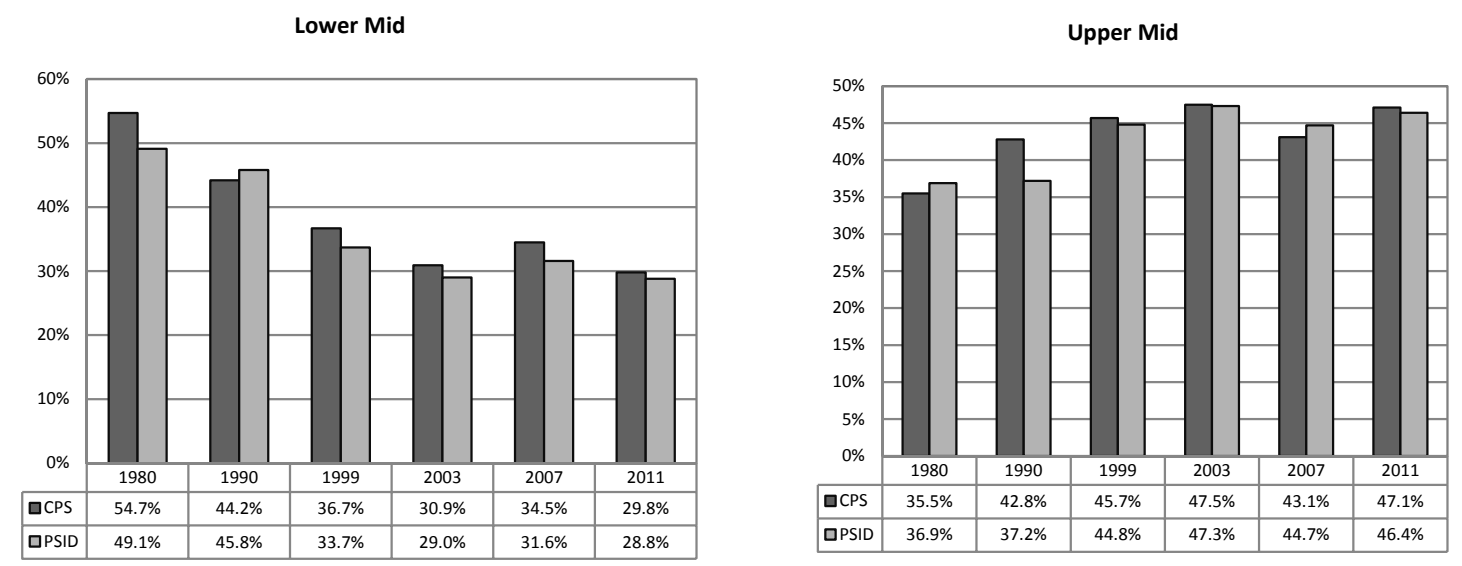

Figure 4. Lower and Upper Mid Wife Wage Group Share in Total (CPS and PSID, in percentage, 1980-2011).

Since the lower mid group is the only one where stable and significantly positive elasticities are found to hold whereas the upper part of the sample contributes to negate the presence of a positive elasticity, it is no wonder that a shrinking elasticity phenomenon has been observed from aggregate sample estimations of the 1980-2000 period. This finding tells us that what has changed over time is not wage elasticities with respect to the lower and upper mid groups, but the distribution of working wives in relatively lower paid jobs. This is in line with Juhn and Murphy's [8] observation of increasing wage opportunities for women as well as findings by Welch [47] on a weakening segregation between male and female labour markets by wage rate. This development is further revealed by the shifting distributions of wife's wage rates from 1980 to 2011 as compared to the distributions of husband's wage, see Figure 5. The distributions of wage rates by gender have clearly been converging over the last three decades.

Thirdly, the finding of the two groups within which statistically constant elasticities are present provides us with a new angle to tackle the sample selection bias concern with respect to sample representativeness. Our recursive partition search identifies the tail ends of the female wage rates in 
the full-working wife samples as being largely at odd with the rest of the sample. From the practical viewpoint of finding sample evidence which would be representative of the population concerned and thus endorses statistical inference, we should partition out the tail end non-representative observations as judged by the a priori conditional theory of interest, so as to tighten the conditional range upon which statistical inferences are made. It should be noted also that this research strategy carries special implication to models using panel data. Since most of panel-data based models assume single valued parameters of interest, it is vital to exclude individual elements in the panel which are far from representative of the population of interest. Failure of such exclusion would result in sample selection bias.

CPS 1980

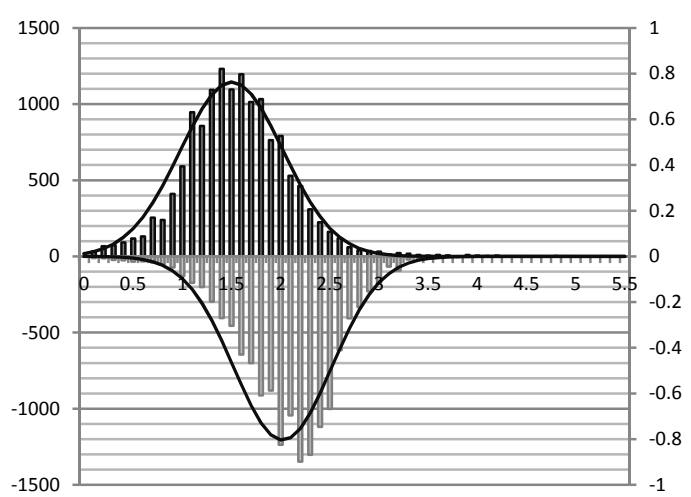

CPS 2011

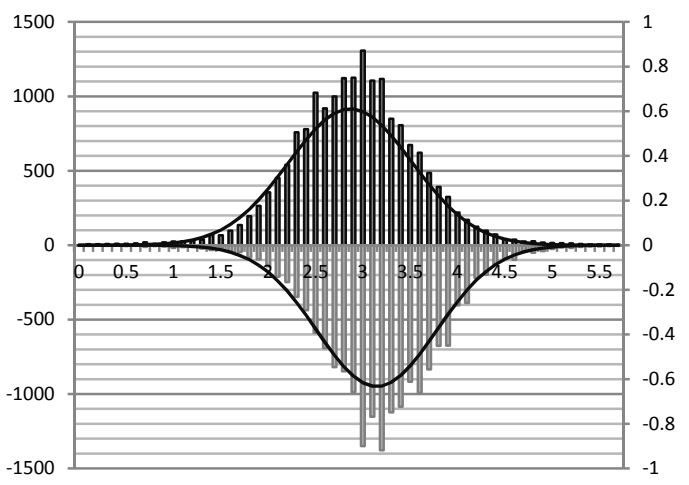

PSID 1980

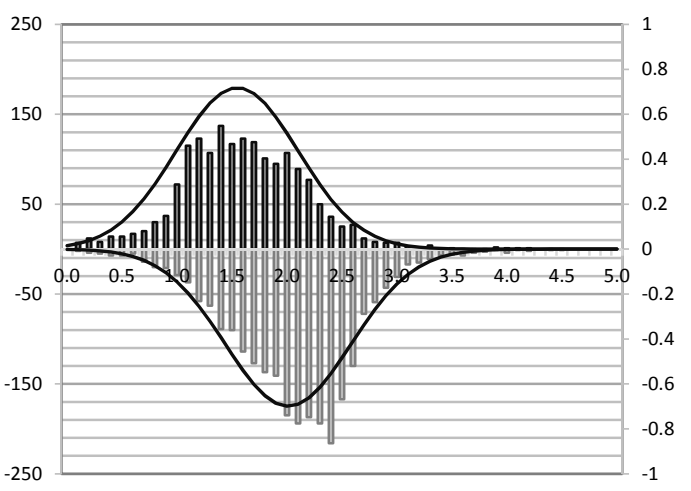

PSID 2011

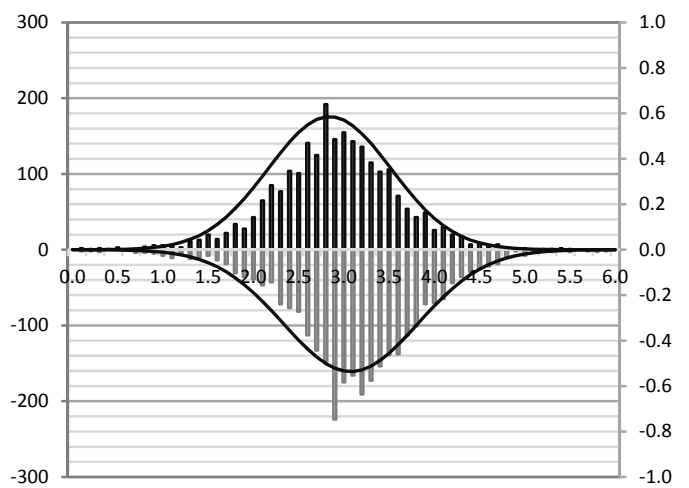

- norm density

Figure 5. Distribution of Wife's and Husbands' Wage Rate in 1980 and 2011 (hourly wage in log, Left: frequency, Right: normal density).

Fourthly, the finding that there is no single-valued wage elasticity across the wage earners suggests that it could be over-simplistic to treat the non-working wives as a homogenous group and carry out empirical investigation on aggregate extensive margins by means of binary regression models. From the viewpoint of measuring wage elasticity for labour participation, disaggregate studies may be better off partitioning data by wage rate ranges rather than labour participation types. Since our wage imputation method is based on the idea of counterfactual matching of comparable groups, we can exploit the constant elasticity based sample partitions to examine how the imputed wage rates are distributed. It is seen from Table 12 that the percentage of imputed wage rates of non-working wives falling into the lower part of the wage partition is generally higher than that of non-working wives falling into the upper part. Clearly, more experiments are needed to evaluate the robustness of those imputed wages. 
Table 12. Wage distribution of the imputed offering wage rates for nonworking women, percentage shares calculated by the partitions given in Tables 8 and 9 .

\begin{tabular}{ccccccccc}
\hline & \multicolumn{9}{c}{ PSID } & \multicolumn{3}{c}{ CPS } \\
\cline { 2 - 8 } & Lower Part & $\begin{array}{c}\text { Upper } \\
\text { Part }\end{array}$ & $\begin{array}{c}\text { Lower Mid } \\
\text { Group }\end{array}$ & $\begin{array}{c}\text { Upper Mid } \\
\text { Group }\end{array}$ & $\begin{array}{c}\text { Lower } \\
\text { Part }\end{array}$ & $\begin{array}{c}\text { Upper } \\
\text { Part }\end{array}$ & $\begin{array}{c}\text { Lower Mid } \\
\text { Group }\end{array}$ & $\begin{array}{c}\text { Upper Mid } \\
\text { Group }\end{array}$ \\
\hline 1980 & $84.77 \%$ & $15.23 \%$ & $78.52 \%$ & $13.80 \%$ & $68.86 \%$ & $31.14 \%$ & $68.11 \%$ & $30.95 \%$ \\
1990 & $89.83 \%$ & $10.17 \%$ & $70.10 \%$ & $8.47 \%$ & $76.82 \%$ & $23.18 \%$ & $74.80 \%$ & $22.78 \%$ \\
1999 & $75.71 \%$ & $24.29 \%$ & $69.37 \%$ & $19.26 \%$ & $60.93 \%$ & $39.07 \%$ & $60.69 \%$ & $37.37 \%$ \\
2003 & $76.67 \%$ & $23.33 \%$ & $71.49 \%$ & $19.01 \%$ & $46.12 \%$ & $54.09 \%$ & $45.91 \%$ & $50.09 \%$ \\
2007 & $76.09 \%$ & $23.91 \%$ & $71.10 \%$ & $17.88 \%$ & $53.77 \%$ & $46.48 \%$ & $53.52 \%$ & $41.12 \%$ \\
2011 & $83.60 \%$ & $16.40 \%$ & $71.08 \%$ & $14.46 \%$ & $50.61 \%$ & $49.99 \%$ & $50.01 \%$ & $45.94 \%$ \\
\hline
\end{tabular}

Table 13. Probit estimates of the wage coefficient in labour force participation regressions.

\begin{tabular}{|c|c|c|c|c|c|c|c|c|}
\hline & \multirow[t]{2}{*}{ Samples } & \multicolumn{2}{|c|}{ Full } & \multicolumn{2}{|c|}{ Lower Mid Wage Group } & \multirow{2}{*}{ 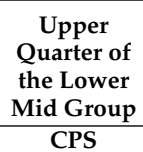 } & \multicolumn{2}{|c|}{ Upper Mid Wage Group } \\
\hline & & PSID & CPS & PSID & CPS & & PSID & CPS \\
\hline \multirow{4}{*}{1980} & $\eta_{I}$ & $0.486^{* *}$ & $0.0738^{* *}$ & $1.409^{* *}$ & $-0.459^{* *}$ & 0.821 & $1.514^{* *}$ & $1.710^{* *}$ \\
\hline & 95\% C.I.^ & $(0.4,0.6)$ & $(0.03,0.1)$ & $(1.1,1.7)$ & $(-0.6,-0.4)$ & $(-0.2,1.8)$ & $(0.8,2.2)$ & $(1.5,1.9)$ \\
\hline & Elasticity & 0.1833 ** & $0.0380 * *$ & $0.517 * *$ & $-0.211^{* *}$ & 0.451 & $0.521 * *$ & $0.984 * *$ \\
\hline & 95\% C.I.^ & $(0.14,0.2)$ & $(0.02,0.1)$ & $(0.41,0.6)$ & $(-0.3,-0.2)$ & $(-0.1,1.0)$ & $(0.3,0.7)$ & $(0.9,1.1)$ \\
\hline \multirow{4}{*}{1990} & $\eta_{I}$ & $0.6824^{* *}$ & $0.382^{* *}$ & $1.478^{* *}$ & $0.169^{* *}$ & $3.763^{* *}$ & $1.2456^{* *}$ & $0.760^{* *}$ \\
\hline & $95 \%$ C.I.^ & $(0.6,0.8)$ & $(0.3,0.4)$ & $(1.2,1.7)$ & $(0.1,0.3)$ & $(2.7,4.8)$ & $(0.6,1.9)$ & $(0.6,0.9)$ \\
\hline & Elasticity & 0.26 ** & $0.219 * *$ & $0.652 * *$ & $0.101^{* *}$ & $2.313 * *$ & $0.2878 * *$ & $0.408^{* *}$ \\
\hline & $95 \%$ C.I.^ & $(0.2,0.3)$ & $(0.2,0.24)$ & $(0.55,0.8)$ & $(0.04,0.2)$ & $(1.67,3.0)$ & $(0.14,0.4)$ & $(0.32,0.5)$ \\
\hline \multirow{4}{*}{1999} & $\eta_{I}$ & $0.658^{* *}$ & $0.230^{* *}$ & $1.1825^{* *}$ & $-2.008^{* *}$ & 1.145 & $1.076^{* *}$ & $1.651^{* *}$ \\
\hline & 95\% C.I.^ & $(0.54,0.8)$ & $(0.18,0.3)$ & $(0.8,1.54)$ & $(-2.2,-1.8)$ & $(-0.1,2.3)$ & $(0.5,1.7)$ & $(1.5,1.8)$ \\
\hline & Elasticity & $0.318 * *$ & $0.153 * *$ & $0.664^{* *}$ & $-1.280 * *$ & 0.922 & $0.3849 * *$ & $1.030 * *$ \\
\hline & $95 \%$ C.I.^ & $(0.27,0.4)$ & $(0.12,0.2)$ & $(0.5,0.85)$ & $(-1.4,-1.2)$ & $(-0.03,2)$ & $(0.18,0.6)$ & $(0.92,1.1)$ \\
\hline \multirow{4}{*}{2003} & $\eta_{I}$ & $0.8848^{* *}$ & $0.191^{* *}$ & $1.4856^{* *}$ & $-3.858 * *$ & $-1.893^{* *}$ & $1.477^{* *}$ & $1.710^{* *}$ \\
\hline & 95\% C.I.^ & $(0.77,1.0)$ & $(0.16,0.2)$ & $(1.1,1.86)$ & $(-4.1,-3.6)$ & $(-2.8,-1)$ & $(0.83,2.1)$ & $(1.58,1.8)$ \\
\hline & Elasticity & $0.422 * *$ & 0.142 ** & $0.9573 * *$ & $-2.247 * *$ & $-1.662 * *$ & 0.4534 ** & 1.253 ** \\
\hline & $95 \%$ C.I.^ & $(0.37,0.5)$ & $(0.12,0.2)$ & $(0.74,1.2)$ & $(-2.4,-2.1)$ & $(-2.5,-1)$ & $(0.26,0.7)$ & $(1.16,1.3)$ \\
\hline \multirow{4}{*}{2007} & $\eta_{I}$ & $0.811^{* *}$ & $0.195^{* *}$ & $1.257^{* *}$ & $-2.623^{* *}$ & $2.269^{* *}$ & $1.578^{* *}$ & $1.759^{* *}$ \\
\hline & 95\% C.I.^ & $(0.7,0.93)$ & $(0.16,0.2)$ & $(0.92,1.2)$ & $(-2.8,-2.5)$ & $(1.4,3.16)$ & $(0.94,2.2)$ & $(1.6,1.92)$ \\
\hline & Elasticity & $0.4225 * *$ & $0.153 * *$ & $0.8601 * *$ & $-1.796 * *$ & $2.074 * *$ & $0.5342 * *$ & $1.316 * *$ \\
\hline & 95\% C.I.^ & $(0.4,0.47)$ & $(0.1,0.18)$ & $(0.65,1.1)$ & $(-1.9,-1.7)$ & $(1.3,2.9)$ & $(0.3,0.75)$ & $(1.2,1.43)$ \\
\hline \multirow{4}{*}{2011} & $\eta_{I}$ & $0.9697^{* *}$ & $0.243^{* *}$ & $1.202 * *$ & $-3.317^{* *}$ & 0.590 & $3.048 * *$ & $1.261^{* *}$ \\
\hline & $95 \%$ C.I. ${ }^{\wedge}$ & $(0.87,1.1)$ & $(0.21,0.3)$ & $(0.87,1.5)$ & $(-3.5,-3.1)$ & $(-0.4,1.6)$ & $(2.3,3.8)$ & $(1.12,1.4)$ \\
\hline & Elasticity & $0.4998 * *$ & $0.201^{* *}$ & 0.906 ** & $-2.328 * *$ & 0.567 & $0.869 * *$ & $1.032 * *$ \\
\hline & 95\% C.I.^ & $(0.46,0.5)$ & $(0.17,0.2)$ & $(0.68,1.1)$ & $(-2.5,-2.2)$ & $(-0.4,1.5)$ & $(0.65,1.1)$ & $(0.9,1.14)$ \\
\hline
\end{tabular}

C.I. stands for confidence interval; ${ }^{\wedge}$ stands for HCSE robust standard errors used; ${ }^{*}$ and ${ }^{* *}$ indicate significant at $5 \%$ and $1 \%$ respectively. Wage group divisions are given in Table 9.

Nevertheless, experiments which use those imputed wage data with a binary version of $\left(1^{\prime}\right)$, where the work hours variable is replaced by a corresponding labour force participation variable, yield, as expected, significantly different wage coefficients between the full-sample and subsample estimates, as shown in Table 13.

While positive coefficients are found over the full sample estimation, the subsample estimates turn negative for the lower mid wage group using the CPS data source. Experiments with further divided subsamples reveal that these negative estimates are dependent on the very low end of wage rates. Once the lower mid wage group is limited to its upper quartile, the negativity disappears, except for the 2003 wave. This finding suggests that many wives facing very low offering wage rates are discouraged to join the labour force, since these rates fall well below their respective reservation wage rates. Although somewhat preliminary, these experiments adequately illustrate how useful the disaggregate information can be to help better design unemployment policies with respect to targeting the right groups.

Fifthly, the constant elasticity based sample partitions also provide us with an easy way to check the necessity or feasibility of grouping data by certain characteristics. For example, our earlier data 
ordering scheme by age results in relatively stable elasticity estimates, indicating it unnecessary to disaggregate data by age groups. In other words, there lacks strong evidence supporting the hypothesis that different age cohorts have different elasticities. This check is especially useful for the empirical feasibility of the quantile estimation method, a method which has gained increasing popularity as an intuitively appealing way to tackle heteroscedasticity and low fit in large micro data sample modelling. The method is based on a conditional quantile function of interest, a function generally without much a priori theoretical support. In our case, the method amounts to postulating $Q_{\tau}\left(\ln \left(H_{i}\right) \mid \ln \left(w_{i}\right), \eta_{w \tau}\right)$ as against $E\left(\ln \left(H_{i}\right) \mid \ln \left(w_{i}\right), \eta_{w}\right)$, which underlies model (1'). Since statistically constant elasticities are found with our two groups, we can calculate the shares of work hours within these two groups classified by the four quantiles of $H_{i}$ of the working wife sample. The quantile method would be considered suitable if the shares in one group are dominantly from one quantile. It is clearly seen from Table 14 that there are no dominant quantiles in either of the two groups to warrant the use of quantile regressions.

Table 14. Shares of working wives with wage rates in the lower and upper mid groups in Table 8 , by four quantile ranges of hours of work, $H_{i}$ (in \%).

\begin{tabular}{cccccccccc}
\hline \multirow{2}{*}{ Wave } & Data & \multicolumn{4}{c}{ Lower Mid Group } & \multicolumn{4}{c}{ Upper Mid Group } \\
\cline { 3 - 9 } & source & Q1 & Q2 & Q3 & Q4 & Q1 & Q2 & Q3 & Q4 \\
\hline \multirow{2}{*}{$\mathbf{1 9 8 0}$} & PSID & 25.9 & 26.2 & 21.6 & 26.3 & 16.6 & 22.3 & 33.6 & 27.5 \\
& CPS & 25.6 & 27.2 & 27.2 & 19.5 & 18.6 & 20.2 & 33.5 & 27.4 \\
\multirow{2}{*}{$\mathbf{1 9 9 0}$} & PSID & 30.2 & 23.2 & 22.7 & 23.9 & 14.9 & 24.5 & 33.0 & 27.6 \\
& CPS & 30.3 & 28.2 & 18.7 & 22.8 & 16.4 & 23.2 & 24.9 & 35.6 \\
\multirow{2}{*}{$\mathbf{1 9 9 9}$} & PSID & 31.8 & 23.8 & 20.3 & 24.1 & 16.7 & 25.2 & 31.9 & 26.1 \\
& CPS & 30.8 & 27.4 & 22.7 & 19.2 & 17.1 & 24.4 & 24.5 & 34.0 \\
$\mathbf{2 0 0 3}$ & PSID & 32.5 & 22.2 & 25.1 & 20.2 & 17.2 & 25.2 & 29.4 & 28.2 \\
& CPS & 30.4 & 28.3 & 21.9 & 19.4 & 17.9 & 24.8 & 29.0 & 28.3 \\
$\mathbf{2 0 0 7}$ & PSID & 31.2 & 21.1 & 25.7 & 22.0 & 17.3 & 26.6 & 30.9 & 25.2 \\
& CPS & 30.1 & 27.3 & 22.9 & 19.7 & 18.4 & 24.2 & 28.8 & 28.6 \\
& PSID & 32.1 & 25.1 & 20.5 & 22.3 & 18.0 & 22.5 & 38.2 & 21.3 \\
& CPS & 32.2 & 27.2 & 22.0 & 18.6 & 19.0 & 24.1 & 20.9 & 27.9 \\
\hline
\end{tabular}

Finally, we try to seek answers to the following question by exploiting the non-unique ways of data ordering with cross-section data. Do the wives from the two groups have statistically stable income elasticity? We follow the same strategy as before to try and locate income ranges within which the recursive estimates of $\eta_{I}$ are statistically constant, when the full-working women sample estimates turn out to be unstable under the data ordering scheme by $I_{i}$. The key results of the search are reported in Table 15. 
Table 15. OLS estimates of $\eta_{I}$ in $\left(1^{\prime}\right)$ and related statistics, working wife samples and partitioned subsamples, data ordered by $I_{i}$ (income in \$1000 USD).

\begin{tabular}{|c|c|c|c|c|c|c|c|}
\hline & Samples & Full Sample & Lower End & Upper End & Lower Mid & Upper Mid & Joint Mid \\
\hline 1980 & & Full range & $<\$ 17$ & $>\$ 17$ & $\$ 6.5-17$ & $\$ 17-45$ & $\$ 6.5-45$ \\
\hline \multirow{3}{*}{ PSID } & $\eta_{I}^{O L S}$ & -0.158 & 0.047 & -0.308 & -0.052 & -0.194 & -0.205 \\
\hline & 95\% C.I.^ & $(-0.25,-0.1)$ & $(-0.09,0.18)$ & $(-0.52,-0.1)$ & $(-0.32,0.22)$ & $(-0.45,0.06)$ & $(-0.32,-0.1)$ \\
\hline & Hansen & 0.246 & 0.109 & 0.066 & 0.071 & 0.046 & 0.065 \\
\hline \multirow{3}{*}{ CPI } & $\eta_{I}^{O L S}$ & $-0.143^{* *}$ & -0.019 & $-0.217^{* *}$ & -0.034 & $-0.218^{* *}$ & $-0.177^{* *}$ \\
\hline & 95\% C.I.^ & $(-0.17,-0.1)$ & $(-0.08,0.04)$ & $(-0.3,-0.15)$ & $(-0.13,0.07)$ & $(-0.3,-0.13)$ & $(-0.2,-0.13)$ \\
\hline & Hansen & $0.685^{*}$ & 0.052 & 0.052 & 0.042 & 0.051 & 0.164 \\
\hline \multirow[t]{2}{*}{1990} & & Full range & $<\$ 27$ & $>\$ 27$ & $\$ 10.4-27$ & $\$ 27-71$ & $\$ 10.4-71$ \\
\hline & $\eta_{I}^{O L S}$ & -0.127 & -0.057 & -0.225 & -0.117 & -0.354 & -0.191 \\
\hline \multirow[t]{2}{*}{ PSID } & 95\% C.I.^ & $(-0.17,-0.1)$ & $(-0.12,0.00)$ & $(-0.33,-0.1)$ & $(-0.28,0.04)$ & $(-0.51,-0.2)$ & $(-0.26,-0.1)$ \\
\hline & Hansen & 0.427 & 0.170 & 0.091 & 0.151 & 0.026 & 0.177 \\
\hline \multirow{3}{*}{ CPI } & $\eta_{I}^{O L S}$ & $-0.135^{* *}$ & -0.024 & $-0.267^{* *}$ & -0.043 & $-0.264^{* *}$ & $-0.161^{* *}$ \\
\hline & 95\% C.I.^ & $(-0.16,-0.1)$ & $(-0.08,0.02)$ & $(-0.32,-0.2)$ & $(-0.13,0.05)$ & $(-0.34,-0.2)$ & $(-0.2,-0.13)$ \\
\hline & Hansen & $1.364^{* *}$ & 0.146 & 0.048 & 0.150 & 0.049 & 0.323 \\
\hline \multirow[t]{2}{*}{1999} & & Full range & $<\$ 34.5$ & $>\$ 34.5$ & $\$ 13.2-34.5$ & $\$ 34.5-91$ & $\$ 13.2-91$ \\
\hline & $\eta_{I}^{O L S}$ & -0.103 & 0.029 & -0.157 & 0.096 & -0.198 & -0.091 \\
\hline \multirow[t]{2}{*}{ PSID } & 95\% C.I.^ & $(-0.2,-0.06)$ & $(-0.07,0.13)$ & $(-0.24,-0.1)$ & $(-0.08,0.28)$ & $(-0.3,-0.06)$ & $(-0.2,-0.02)$ \\
\hline & Hansen & 0.366 & 0.068 & 0.061 & 0.050 & 0.058 & 0.251 \\
\hline \multirow{3}{*}{ CPI } & $\eta_{I}^{O L S}$ & $-0.086^{* *}$ & $0.059^{*}$ & -0.143 & 0.045 & $-0.180^{* *}$ & $-0.117^{* *}$ \\
\hline & 95\% C.I.^ & $(-0.1,-0.07)$ & $(0.01,0.11)$ & $(-0.2,-0.10)$ & $(-0.05,0.15)$ & $(-0.25,-0.1)$ & $(-0.15,-0.1)$ \\
\hline & Hansen & $1.398^{* *}$ & 0.031 & 0.114 & 0.029 & 0.052 & 0.305 \\
\hline \multirow[t]{2}{*}{2003} & & Full range & $<\$ 38.1$ & $>\$ 38.1$ & $\$ 14.6-38.1$ & $\$ 38.1-100.5$ & $\$ 14.6-100.5$ \\
\hline & $\eta_{I}^{O L S}$ & -0.121 & -0.060 & -0.204 & -0.258 & -0.267 & -0.156 \\
\hline PSID & 95\% C.I.^ & $(-0.23,-0.01)$ & $(-0.17,0.05)$ & $\begin{array}{l}(-0.31 \\
-0.10)\end{array}$ & $\begin{array}{l}(-0.44, \\
-0.08)\end{array}$ & $\begin{array}{l}(-0.46, \\
-0.08)\end{array}$ & $\begin{array}{l}(-0.23 \\
-0.08)\end{array}$ \\
\hline \multirow{4}{*}{ CPI } & Hansen & 0.0911 & 0.189 & 0.105 & 0.052 & 0.157 & 0.199 \\
\hline & $\eta_{I}^{O L S}$ & $-0.106^{* *}$ & 0.004 & $-0.169 * *$ & -0.012 & $-0.218^{* *}$ & $-0.127^{* *}$ \\
\hline & 95\% C.I.^ & $(-0.13,-0.09)$ & $(-0.03,0.04)$ & $\begin{array}{l}(-0.20 \\
-0.14)\end{array}$ & $(-0.08,0.06)$ & $\begin{array}{l}(-0.28 \\
-0.16)\end{array}$ & $\begin{array}{l}(-0.15 \\
-0.10)\end{array}$ \\
\hline & Hansen & $2.008^{* *}$ & 0.034 & 0.243 & 0.025 & 0.131 & $0.717^{*}$ \\
\hline \multirow[t]{2}{*}{2007} & & Full range & $<\$ 42.9$ & $>\$ 42.9$ & $\$ 16.4-42.9$ & $\$ 42.9-113.3$ & $\$ 16.4-113.3$ \\
\hline & $\eta_{I}^{O L S}$ & -0.103 & -0.021 & -0.197 & 0.061 & -0.197 & -0.086 \\
\hline \multirow[t]{3}{*}{ PSID } & 95\% C.I.^ & $(-0.2,-0.06)$ & $(-0.09,0.05)$ & $(-0.3,-0.11)$ & $(-0.12,0.24)$ & $(-0.4,-0.04)$ & $(-0.2,-0.01)$ \\
\hline & Hansen & 0.382 & 0.138 & 0.017 & 0.065 & 0.028 & 0.194 \\
\hline & $\eta_{I}^{O L S}$ & $-0.104^{* *}$ & 0.028 & $-0.158^{* *}$ & -0.037 & $-0.202^{* *}$ & $-0.141^{* *}$ \\
\hline \multirow[t]{2}{*}{ CPI } & 95\% C.I.^ & $(-0.13,-0.1)$ & $(-0.02,0.07)$ & $(-0.2,-0.13)$ & $(-0.11,0.02)$ & $(-0.25,-0.2)$ & $(-0.17,-0.1)$ \\
\hline & Hansen & $1.517^{* *}$ & 0.203 & 0.179 & 0.055 & 0.113 & 0.346 \\
\hline \multirow[t]{2}{*}{2011} & & Full range & $<\$ 46.5$ & $>\$ 46.5$ & $\$ 17.8-46.5$ & $\$ 46.5-122.8$ & $\$ 17.8-122.8$ \\
\hline & $\eta_{I}^{O L S}$ & -0.094 & 0.002 & -0.222 & 0.044 & -0.283 & -0.099 \\
\hline \multirow[t]{2}{*}{ PSID } & 95\% C.I.^ & $(-0.2,-0.04)$ & $(-0.12,0.13)$ & $(-0.3,-0.13)$ & $(-0.16,0.25)$ & $(-0.45,-0.1)$ & $(-0.2,-0.02)$ \\
\hline & Hansen & 0.463 & 0.079 & 0.063 & 0.066 & 0.035 & 0.240 \\
\hline \multirow{3}{*}{ CPI } & $\eta_{I}^{O L S}$ & $-0.101^{* *}$ & 0.025 & $-0.211^{* *}$ & $0.092 *$ & $-0.209^{* *}$ & $-0.099 * *$ \\
\hline & 95\% C.I.^ & $(-0.1,-0.08)$ & $(-0.01,0.06)$ & $(-0.25,-0.2)$ & $(0.02,0.16)$ & $(-0.26,-0.2)$ & $(-0.13,-0.1)$ \\
\hline & Hansen & $2.877^{* *}$ & 0.267 & 0.056 & 0.065 & 0.019 & $1.059 * *$ \\
\hline
\end{tabular}

C.I. stands for confidence interval; ${ }^{\wedge}$ stands for HCSE robust standard errors used; * and ${ }^{* *}$ indicate significant at $5 \%$ and $1 \%$ respectively. Income partition values are real-value comparable after deflated by the US inflation rates.

In particular, two mid income groups are identified, with the lower mid group sharing zero elasticity estimates and the upper mid group sharing roughly -0.2 elasticity estimates. We then calculate, for the two wage groups respectively, the shares of the income partitioned by the income ranges reported in Table 16. We find that the two mid wage groups overlap dominantly with the two mid groups of the income ranges where constant estimates of $\eta_{I}$ lie. Hence, the answer to the above question is positive. Moreover, the finding that sizeable shares of income in both groups fall into the income range where estimates of $\eta_{I}$ are stable but insignificant from zero helps explain why the estimated income elasticities of these two wage groups are not highly significant (the details of those estimates are not reported here to keep the paper short). 
Table 16. Income compositions of the two wage groups in Table 9, by the income partitions given in Table 15.

\begin{tabular}{|c|c|c|c|c|c|c|c|c|c|c|}
\hline \multirow{2}{*}{ Inc.: } & \multicolumn{5}{|c|}{ Lower Mid Wage Group } & \multicolumn{5}{|c|}{ Upper Mid Wage Group } \\
\hline & $\begin{array}{c}\text { Lower } \\
\text { Tail }\end{array}$ & $\begin{array}{l}\text { Lower } \\
\text { Mid }\end{array}$ & $\begin{array}{l}\text { Upper } \\
\text { Mid }\end{array}$ & $\begin{array}{c}\text { Upper } \\
\text { Tail }\end{array}$ & $\begin{array}{l}\text { Mid } \\
\text { Two }\end{array}$ & $\begin{array}{c}\text { Lower } \\
\text { Tail }\end{array}$ & $\begin{array}{l}\text { Lower } \\
\text { Mid }\end{array}$ & $\begin{array}{l}\text { Upper } \\
\text { Mid }\end{array}$ & $\begin{array}{c}\text { Upper } \\
\text { Tail }\end{array}$ & $\begin{array}{l}\text { Mid } \\
\text { Two }\end{array}$ \\
\hline \multicolumn{11}{|c|}{1980} \\
\hline PSID & $5.3 \%$ & $45.2 \%$ & $46.7 \%$ & $2.86 \%$ & $91.9 \%$ & $3.8 \%$ & $29.3 \%$ & $62.6 \%$ & $4.26 \%$ & $91.9 \%$ \\
\hline CPS & $4.4 \%$ & $39.2 \%$ & $53.5 \%$ & $3.0 \%$ & $92.7 \%$ & $2.2 \%$ & $30.9 \%$ & $61.7 \%$ & $5.2 \%$ & $92.6 \%$ \\
\hline \multicolumn{11}{|c|}{1990} \\
\hline PSID & $9.6 \%$ & $45.9 \%$ & $41.1 \%$ & $3.4 \%$ & $87.0 \%$ & $6.96 \%$ & $46.2 \%$ & $43.2 \%$ & $3.62 \%$ & $89.4 \%$ \\
\hline CPS & $6.9 \%$ & $40.9 \%$ & $47.4 \%$ & $4.9 \%$ & $88.3 \%$ & $2.9 \%$ & $28.2 \%$ & $60.6 \%$ & $8.4 \%$ & $88.8 \%$ \\
\hline \multicolumn{11}{|c|}{1999} \\
\hline PSID & $4.9 \%$ & $39.8 \%$ & $48.6 \%$ & $6.71 \%$ & $88.4 \%$ & $2.29 \%$ & $27.7 \%$ & $57.2 \%$ & $12.8 \%$ & $84.9 \%$ \\
\hline CPS & $6.6 \%$ & $39.8 \%$ & $46.6 \%$ & $7.0 \%$ & $86.4 \%$ & $3.0 \%$ & $25.6 \%$ & $60.0 \%$ & $11.4 \%$ & $85.6 \%$ \\
\hline \multicolumn{11}{|c|}{2003} \\
\hline PSID & $6.4 \%$ & $44.2 \%$ & $41.9 \%$ & $7.52 \%$ & $86.1 \%$ & $3.98 \%$ & $29.2 \%$ & $57.9 \%$ & $8.93 \%$ & $87.1 \%$ \\
\hline CPS & $5.5 \%$ & $39.8 \%$ & $47.8 \%$ & $6.9 \%$ & $87.6 \%$ & $2.9 \%$ & $28.4 \%$ & $58.2 \%$ & $10.5 \%$ & $86.6 \%$ \\
\hline \multicolumn{11}{|c|}{2007} \\
\hline PSID & $6.7 \%$ & $47.6 \%$ & $40.3 \%$ & $5.44 \%$ & $87.9 \%$ & $2.95 \%$ & $21.9 \%$ & $61.7 \%$ & $13.5 \%$ & $83.6 \%$ \\
\hline CPS & $5.4 \%$ & $40.6 \%$ & $46.3 \%$ & $7.7 \%$ & $87.0 \%$ & $2.7 \%$ & $28.1 \%$ & $58.0 \%$ & $11.2 \%$ & $86.2 \%$ \\
\hline \multicolumn{11}{|c|}{2011} \\
\hline PSID & $12.0 \%$ & $43.1 \%$ & $38.1 \%$ & $6.74 \%$ & $81.2 \%$ & $4.65 \%$ & $32.8 \%$ & $54.9 \%$ & $7.66 \%$ & $87.7 \%$ \\
\hline CPS & $7.8 \%$ & $42.6 \%$ & $42.8 \%$ & $6.8 \%$ & $85.5 \%$ & $3.5 \%$ & $29.5 \%$ & $57.6 \%$ & $9.5 \%$ & $87.0 \%$ \\
\hline
\end{tabular}

Since wage and income are probably the most susceptive to mutual collinearity among all the explanatory variables in $\left(1^{\prime}\right)$, we carry out a joint sub-group experiment to see how invariant the estimates of wage elasticity and income elasticity are when the two wage sub-groups are joined up with the two income sub-groups. Table 17 reports the main results of this experiment.

Comparing it with Tables 9 and 15 we see that, in general, the effect of joining up the two sub-groups is more obvious from the estimates using the PSID data sets than from those using the CPS data sets. The difference may well be due to the much smaller sample sizes of the PSID source. Further scrutiny of the CPS results in Table 17 tells us that the income elasticity estimates for the lower and upper mid income group and the wage elasticity estimates for the lower mid wage group are largely unaffected regardless the income and wage group pairing, showing values around zero, -0.2 and 0.4 respectively. However, the wage elasticity estimates of the upper mid wage group are somewhat affected. They become negative around -0.1 if paired with the lower mid income group and positive around 0.1 if paired with the upper mid income group. This result firstly reveals that the lower mid wage group is more homogenous than the upper mid wage group as far as the wage elasticity is concerned. Secondly, a positive substitution effect is conditional on a relatively high income earned by other family members. Economically this could be explained by the aversion of wives to earn higher income than their spouse due to gender identity norms. For instance, Bertrand et al. [48] find in couples where the wife earns more than the husband, the wife substitutes household chores for labour market work.

The above experiment illustrates how versatile the method is to combine data ordering schemes with recursive partition search for statistically stable estimates of the parameters of interest. It can help us identify various joint ranges of subgroups from data samples to address practical questions relating to various compositional issues in compound with the parameters of interest. 
Table 17. Joint subsample estimates of income and wage elasticities, by wage and income group partitions given in Tables 9 and 15.

\begin{tabular}{|c|c|c|c|c|c|c|c|c|c|}
\hline \multirow{2}{*}{\multicolumn{2}{|c|}{$\begin{array}{c}\text { Wage Group } \\
\text { Income Group }\end{array}$}} & \multicolumn{4}{|c|}{ Lower Mid } & \multicolumn{4}{|c|}{ Upper Mid } \\
\hline & & \multicolumn{2}{|c|}{ Lower Mid } & \multicolumn{2}{|c|}{ Upper Mid } & \multicolumn{2}{|c|}{ Lower Mid } & \multicolumn{2}{|c|}{ Upper Mid } \\
\hline Wave & & CPS & PSID & CPS & PSID & CPS & PSID & CPS & PSID \\
\hline \multirow{4}{*}{1980} & $\eta_{w}^{\mathrm{OLS}}$ & $0.739^{* *}$ & 0.3022 & $0.838^{* *}$ & 0.2176 & $-0.273^{*}$ & -0.3273 & -0.019 & $0.5909^{*}$ \\
\hline & R.S.E. & 0.074 & 0.187 & 0.073 & 0.242 & 0.137 & 0.2066 & 0.093 & 0.2695 \\
\hline & $\eta_{I}^{O L S}$ & -0.099 & -0.1656 & $-0.31^{* *}$ & -0.327 & 0.073 & 0.1941 & -0.140 * & -0.0452 \\
\hline & R.S.E. & 0.062 & 0.154 & 0.065 & 0.21 & 0.092 & 0.168 & 0.063 & 0.175 \\
\hline \multirow{4}{*}{1990} & $\eta_{w}^{O L S}$ & $0.614^{* *}$ & $0.346^{* *}$ & $0.869^{* *}$ & $0.573^{* *}$ & $-0.219^{*}$ & -0.1828 & $0.129^{*}$ & -0.0142 \\
\hline & R.S.E. & 0.065 & 0.106 & 0.070 & 0.139 & 0.089 & 0.137 & 0.056 & 0.122 \\
\hline & $\eta_{I}^{O L S}$ & -0.046 & -0.269 * & $-0.23^{* *}$ & $-0.48^{* *}$ & -0.041 & 0.1159 & $-0.26^{* *}$ & $-0.36^{* *}$ \\
\hline & R.S.E. & 0.062 & 0.111 & 0.068 & 0.155 & 0.070 & 0.117 & 0.047 & 0.092 \\
\hline \multirow{4}{*}{1999} & $\eta_{w}^{\mathrm{OLS}}$ & $0.442^{* *}$ & $0.586^{* *}$ & $0.372^{* *}$ & 0.3257 & -0.082 & 0.0858 & $0.124^{*}$ & 0.0905 \\
\hline & R.S.E. & 0.074 & 0.162 & 0.081 & 0.176 & 0.065 & 0.108 & 0.055 & 0.081 \\
\hline & $\eta_{I}^{O L S}$ & -0.096 & 0.1065 & $-0.179^{*}$ & -0.2097 & 0.105 & -0.0535 & $-0.17^{* *}$ & -0.1512 \\
\hline & R.S.E. & 0.059 & 0.144 & 0.072 & 0.138 & 0.055 & 0.119 & 0.042 & 0.0788 \\
\hline \multirow{4}{*}{2003} & $\eta_{w}^{O L S}$ & $0.462^{* *}$ & 0.1714 & $0.425^{* *}$ & 0.3407 & $-0.129^{*}$ & -0.1842 & $0.087^{*}$ & -0.0426 \\
\hline & R.S.E. & 0.066 & 0.151 & 0.064 & 0.186 & 0.052 & 0.137 & 0.040 & 0.088 \\
\hline & $\eta_{I}^{O L S}$ & -0.085 & $-0.276^{*}$ & $-0.23^{* *}$ & $-0.65^{* *}$ & 0.083 & -0.078 & $-0.20 * *$ & -0.0519 \\
\hline & R.S.E. & 0.058 & 0.122 & 0.058 & 0.173 & 0.046 & 0.104 & 0.034 & 0.075 \\
\hline \multirow{4}{*}{2007} & $\eta_{w}^{\mathrm{OLS}}$ & $0.354^{* *}$ & $0.3282^{*}$ & $0.465^{* *}$ & $1.049^{* *}$ & $-0.146^{*}$ & -0.1445 & 0.046 & -0.084 \\
\hline & R.S.E. & 0.052 & 0.164 & 0.063 & 0.242 & 0.062 & 0.126 & 0.044 & 0.112 \\
\hline & $\eta_{I}^{O L S}$ & $-0.17^{* *}$ & 0.089 & $-0.21^{* *}$ & $-0.50 * *$ & 0.098 * & -0.0578 & $-0.19 * *$ & -0.1218 \\
\hline & R.S.E. & 0.045 & 0.141 & 0.052 & 0.18 & 0.047 & 0.11 & 0.033 & 0.077 \\
\hline \multirow{4}{*}{2011} & $\eta_{w}^{O L S}$ & $0.450^{* *}$ & 0.3461 & $0.454^{* *}$ & $0.5091^{*}$ & $-0.14^{* *}$ & -0.063 & $0.083^{*}$ & 0.1658 \\
\hline & R.S.E. & 0.072 & 0.212 & 0.070 & 0.242 & 0.052 & 0.129 & 0.041 & 0.108 \\
\hline & $\eta_{I}^{O L S}$ & -0.015 & -0.1067 & $-0.25^{* *}$ & $-0.63 * *$ & 0.102 * & 0.119 & $-0.19 * *$ & -0.1657 \\
\hline & R.S.E. & 0.055 & 0.161 & 0.062 & 0.243 & 0.045 & 0.098 & 0.032 & 0.089 \\
\hline
\end{tabular}

\section{Concluding Remarks}

Our extensive investigation has revealed how incredible the IV-based evidence of shrinking wage elasticities of married women is. It thus adequately demonstrates the misleading nature of the endogeneity-backed IV approach. The approach blocks, by denying the conditional status of those a priori postulated explanatory variables of interest, the route of organised data learning to locate where statistically invariant estimates of the parameters of interest lie, see $[17,18]$ for further exposition.

Once the route is unblocked, we are able to make two key discoveries, via extensive use of recursive techniques combined with various data ordering schemes. Firstly, comparatively invariant wage elasticities exist only within certain wage ranges over the last three decades. The elasticity estimates are roughly 0.4 for relatively low wage earners above a certain threshold, zero for relatively high wage earners below a certain threshold and negative above this threshold. Secondly, the relative shares of working wives in these ranges have changed. This change is especially pronounced during the two decades after 1980, whereby these wage ranges remain remarkably constant in terms of constant-prices. These discoveries with their locality present more reliable and accurate wage elasticity estimates to policy makers than what has been available from previous studies. From the viewpoint of academic research, the power of these discoveries is manifold, as extensively discussed in the previous section. In short, they help explain the previous finding of shrinking elasticities using full samples of working wives of the CPS source; they invalidate the use of single-valued wage elasticity estimates using micro data and also the premise of a single female labour supply market in which all the housewives are treated as one homogenous group; they provide an easy method to evaluate the applicability of quantile techniques and also a broader perspective to deal with sampling selection bias than the conventional estimator-centred approach.

There is no need to reiterate the contrasting features between the wage elasticity estimates presented in Section 3 versus those in Section 2. The wide range of wage parameter estimates we have produced in Section 2 by following the textbook approach is adequate to show how 
arbitrary but fertile the endogeneity-backed IV approach is, and how absent the textbook assumed consistency of IV estimators is in reality. In fact, wide disappointment with the textbook approach is already reflected in a focal shift of econometric research from the conventional parametric approach towards the nonparametric approach. ${ }^{14}$ What our investigation, however, shows is that the cause of disappointment lies with conceptual confusions over endogeneity bias rather than the parametric approach. From the relatively robust elasticities for the two wage groups which we have uncovered, we can better appreciate the role of a priori theories expressed in terms of parametric models. They are seldom proved wrong in postulating key conditional variables but are incomplete in specifying either the functional form or other auxiliary explanatory variables necessary due to various special circumstances of the data samples under consideration. It is a strategic mistake to tamper with the incompleteness by modifying the conditional status of those key variables, or to abandon parametric model based theories altogether because of their incompleteness. After all, it is a substantive bonus for the applied economists to find parameters which are both interpretable and inferable beyond samples.

It should be noted that our discovery is essentially based on the OLS, a method rigorously banished for limited dependent models in textbook micro-econometrics-even by those fully acknowledging the shortcoming of the IV method [49]. The history of macro-econometrics shows us that it takes over two decades for the profession to shake off the endogeneity bias paranoia from around 1960, when adequate empirical evidence was first presented to resurrect OLS. It is clearly a huge challenge to initiate a similar resurrection in micro-econometrics. Hopefully, applied micro modellers can overcome the endogeneity bias paranoia sooner than twenty years, with the help of the rapidly growing data availability and data processing technology—see [50]—as well as the lessons learned from the history of macro-econometrics.

Clearly, much refinement is desired of our current results and also methods of investigation. An obvious next step is the analysis of husband's wage elasticity using the same set of data to compare whether the heterogeneity found for the wife's samples also holds for the husbands' samples. Further, more experiments with the wage imputation methods are desired and ways should be explored as how to utilise disaggregate wage range groups to conduct disaggregate studies of the wage elasticities of labour force participation in a comparable manner with those of the hours of work. Last but not least, adaption of more organised data learning techniques is needed, especially from recent developments in statistics into micro-econometrics, such as the method of model-based recursive partition; see [51]. Hopefully, such adaptions would lead to new avenues in microeconomic research.

Acknowledgments: We would like to thank Machiko Nissanke, Ron Smith, Achim Zeileis, Andrey Kuleshov, Lifong Zou, and two anonymous referees for their invaluable help and comments.

Author Contributions: Duo Qin conceived and designed the experiments; Sophie van Huellen and Duo Qin performed the experiments; Qing-Chao Wang designed, programmed and executed the imputation methods; Duo Qin and Sophie van Huellen wrote the paper.

Conflicts of Interest: The authors declare no conflict of interest.

\section{Appendix}

\section{A.1. Data Processing}

Two USA based cross-sectional data sources have been taken into consideration, which are the March Annual Demographic Survey of the Current Population Survey (CPS) published by the Bureau of Labor Statistics, United States Department of Labor and the Panel Study of Income Dynamics (PSID) conducted by the Survey Research Centre at the University of Michigan. For the CPS data the Center for Economic and Policy Research (CEPR) Uniform Extracts are used.

\footnotetext{
14 We owe this point to one of the anonymous referees.
} 
From both datasets the following variables have been extracted: wife's annual hours of work, wife's hourly wage rate, family income net of wife's income, wife's education, wife's age, husband's annual hours of work, husband's hourly wage rate, husband's education, husband's age, a dummy which takes on 1 if children under 6 are in the household and 0 otherwise, and the number of children in the household. For the CPS data and additional dummy variable for the wife's ethnical background is included; for the PSID data a variable for wife's experience is used, which is not available in the CPS data source.

Following [5,6], the annual hours worked variable in CPS is created by multiplying the usual hours worked per week times the number of weeks worked in the past calendar year. Regarding the hourly wage rate, we follow [6] in using the hourly wage rate as reported if available and if the wage per week is reported, this is divided by the usual hours worked per week. For the education variable the coding suggested by the CPS March Codebook for item 18h is used. For family income net wife's income, the wife's personal income from wages and salaries (hourly wage rate times annual hours) is subtracted from total family income.

Both CPS and PSID data sets are processed by the following selection criteria.

- Exclude if woman is non-married, divorced, widowed or separated.

- Include only women with age range 25 to 60.

- Exclude if husband is not working (0 wage).

- Exclude if missing data on wife's education.

- Exclude if missing data on husband's education.

- Exclude if wife's annual working hours exceed 4000.

- Exclude if husband's annual working hours exceed 4000.

- Exclude if wife's wage rate exceeds \$300 USD or is below \$1 USD at 1999 price level per hour.

- Exclude if husband's wage rate exceeds \$300 USD or is below \$1 USD at 1999 price level per hour.

- Exclude if total family income net of wife's income is smaller than 0.

- Exclude if wife has reported positive working hours but no wage and vice versa.

Table A1 provides detailed summary statistics of the different waves for the two datasets.

Table A1. Summary Statistics for the PSID and CPS samples.

\begin{tabular}{|c|c|c|c|c|c|c|c|}
\hline & & 1980 & 1990 & 1999 & 2003 & 2007 & 2011 \\
\hline \multirow{5}{*}{ PSID } & Total Sample & 2517 & 3712 & 2399 & 2638 & 2729 & 2912 \\
\hline & Working wife sample & 1760 & 2895 & 1943 & 2163 & 2265 & 2359 \\
\hline & Rate of labour force participation & $70 \%$ & $78 \%$ & $81 \%$ & $82 \%$ & $83 \%$ & $81 \%$ \\
\hline & Average annual working hours * & 1397 & 1585 & 1691 & 1728 & 1712 & 1699 \\
\hline & Average hourly wage rate ${ }^{*}$ & 5.46 & 9.30 & 14.64 & 17.06 & 19.87 & 21.57 \\
\hline \multirow{5}{*}{ CPS } & Total Sample & 22,117 & 19,914 & 16,607 & 27,738 & 26,050 & 23,886 \\
\hline & Working wife sample & 14,127 & 14,817 & 12,724 & 21,002 & 19,590 & 17,701 \\
\hline & Rate of labour force participation & $64 \%$ & $74 \%$ & $77 \%$ & $76 \%$ & $75 \%$ & $74 \%$ \\
\hline & Average annual working hours * & 1471 & 1623 & 1738 & 1733 & 1773 & 1765 \\
\hline & Average hourly wage rate* & 5.27 & 9.68 & 14.37 & 17.22 & 19.98 & 21.91 \\
\hline
\end{tabular}

* conditional on working.

\section{A.2. Imputation Method}

The missing wage rates are imputed by the hot deck method, e.g., see $[28,52]$. The method derives each missing value, referred to as a recipient, from a few donors who are found to share similar characteristics with the recipient. The method consists of the following two steps.

Step 1: Establish a metric for matching donors to recipients. The purpose of the metric is to produce one summary measure comparable between the recipients and the donors. The metric used 
here is a multiple regression of the upper equation of (2) using the working wife sample only. Several regressions have been experimented with including different choices of regressors. The model has been selected on the condition that all the regressors have statistically stable parameters. The fitted wages are then calculated as representing the summary measures of the donors. The fitted model is used to "predict" a series of the summary measures of all the recipients. We have also tried the alternative of running a binary model, i.e., a labour force participation model, using the full sample including the non-working wives, with the aim to use the fitted probability scores for the second step matching. However, it is difficult to assess how invariant the estimated coefficients and thus how credible the "predicted" probability scores are. The trial matched results tend to be smoother than those by the OLS regression metric, making the imputed missing wage rates appear less similar to the observed wage rates, as compared to those imputed by the OLS regression metric. We have therefore abandoned the binary regression metric.

Step 2: Match recipients with their closest neighbours by their summary measures from Step 1. This is done by a combination of the nearest-neighbour matching method and the radius matching method. Specifically, we set a starting radius to search for a set number of donors from the lower end of the wage scale (the number is set at five here, in line with what is commonly used in the programme evaluation matching literature). For those recipients which have not yet got enough donors, we gradually enlarge the radius until the required number of donors is found. The missing wage value of a recipient is taken as the average of the observed wage rates of the donors.

\section{References}

1. McClelland, R.; Mok, S. A Review of Recent Research on Labor Supply Elasticities; Working Paper. Congressional Budget Office: Washington, DC, USA, 2012.

2. Killingsworth, M.R. Labour Supply; Cambridge University Press: Cambridge, UK, 1983.

3. Heckman, J.J. What has been learned about labor supply in the past twenty years? Am. Econ. Rev. 1993, 83, 116-121.

4. Mincer, J. Labour Force Participation of Married Women: A Study of Labour Supply. In Aspects of Labour Economics; Lewis, H.G., Ed.; Princeton University Press: Princeton, NJ, USA, 1962; pp. 9-41.

5. Blau, F.D.; Kahn, L.M. Changes in the Labor Supply Behaviour of Married Women: 1980-2000. J. Labor Econ. 2007, 25, 393-438. [CrossRef]

6. Heim, B.T. The Incredible Shrinking Elasticities: Married Female Labor Supply, 1978-2002. J. Hum. Resour. 2007, 42, 881-918. [CrossRef]

7. Goldin, C. Understanding the Gender Gap; Oxford University Press: New York, NY, USA, 1990.

8. Juhn, C.; Murphy, K.M. Wage Inequality and Family Labor Supply. J. Labor Econ. 1997, 15, 72-97. [CrossRef]

9. Killingsworth, M.R.; Heckman, J.J. Female Labor Supply: A Survey. In Handbook of Labor Economics; Ashenfelter, O., Layard, R., Eds.; North-Holland: New York, NY, USA, 1986; Volume 1, pp. 103-204.

10. Blundell, R.; MaCurdy, T. Labor Supply: A Review of Alternative Approaches. In Handbook of Labor Economics; Ashenfelter, O., Card, D., Eds.; North-Holland: New York, NY, USA, 1999; Volume 3, pp. 1559-1695.

11. Keane, M.; Rogerson, R. Micro and Macro Labor Supply Elasticities: A Reassessment of Conventional Wisdom. J. Econ. Lit. 2012, 50, 464-476. [CrossRef]

12. Cetty, R.; Guren, A.; Manoli, A.; Weber, A. Are Micro and Macro Labor Supply Elasticities Consistent? A Review of Evidence on the Intensive and Extensive Margins. Am. Econ. Rev. 2011, 101, 471-475.

13. Peterman, W.B. Reconciling Micro and Macro Estimates of the Frisch Labor Supply Elasticity: A Sensitivity Analysis; Federal Reserve Board of Governors: Washington, DC, USA, 2014.

14. Fiorito, R.; Zanella, G. The Anatomy of the Aggregate Labor Supply Elasticity. Rev. Econ. Dyn. 2012, 15, 171-187. [CrossRef]

15. Bound, J.; Jaeger, D.A.; Baker, R.M. Problems with Instrumental Variables Estimation When the Correlation between the Instruments and the Endogeneous Explanatory Variable is Weak. J. Am. Stat. Assoc. 1995, 90, 443-450. [CrossRef] 
16. Van der Klaauw, B. From Micro Data to Causality: Forty Years of Empirical Labor Economics. Labour Econ. 2014, 30, 88-97. [CrossRef]

17. Qin, D. Resurgence of the Endogeneity-backed Instrument Variable Methods. Economics 2015, 9, 1-35.

18. Qin, D. Time to Demystify Endogeneity Bias; Working Paper Series; School of Oriental and African Studies (SOAS) Department of Economics: London, UK, 2015.

19. Mroz, T.A. The Sensitivity of an Empirical Model of Married Women's Hours of Work to Economic and Statistical Assumptions. Econometrica 1987, 55, 765-799. [CrossRef]

20. Berndt, E.R. The Practice of Econometrics: Classic and Contemporary; Addison Wesley: Boston, MA, USA, 1991.

21. Moffitt, R.A. New Developments in Econometric Methods for Labor Market Analysis. In Handbook of Labor Economics; Ashenfelter, O., Card, D., Eds.; North-Holland: New York, NY, USA, 1999; Volume 3, pp. 1368-1397.

22. Heckman, J.J. Sample Selection Bias as a Specification Error. Econometrica 1979, 47, 153-161. [CrossRef]

23. Gersuny, C. Employment Seniority: Cases from Iago to Weber. J. Labour Res. 1982, 3, 111-119. [CrossRef]

24. Newey, W.K.; Powell, J.L.; Walker, J.R. Semiparametric Estimation of Selection Models: New Results. Am. Econ. Rev. 1990, 80, 324-328.

25. Heckman, J.J. A Life-cycle Model of Earnings, Learning, and Consumption. J. Polit. Econ. 1976, 84, 11-44. [CrossRef]

26. Puhani, P. The Heckman Correction for Sample Selection and Its Critique. J. Econ. Surv. 2000, 14, 53-68. [CrossRef]

27. Olsen, R.J. A Least Squares Correction for Selectivity Bias. Econometrica 1980, 48, 1815-1820. [CrossRef]

28. Andridge, R.R.; Little, R.J.A. A Review of Hot Deck Imputation for Survey Non-response. Int. Stat. Rev. 2010, 78, 40-64. [CrossRef] [PubMed]

29. Greene, W.H. On the Asymptotic Bias of the Ordinary Least Squares Estimator. Econometrica 1981, 49, 505-513. [CrossRef]

30. Chung, C.F.; Goldberger, A.S. Proportional Projections in Limited Dependent Variable Models. Econometrica 1984, 52, 531-534. [CrossRef]

31. Qin, D. Formation of Econometrics: A Historical Perspective; Oxford University Press: Oxford, UK, 1993.

32. Qin, D. A History of Econometrics: The Reformation from the 1970s; Oxford University Press: Oxford, UK, 2013.

33. Qin, D. Inextricability of Autonomy and Confluence in Econometrics. Oeconomia 2014, 4, 321-341. [CrossRef]

34. Zeileis, A.; Hornik, K. Generalized M-fluctuation Tests for Parameter Instability. Stat. Neerl. 2007, 61, 488-508. [CrossRef]

35. Pagan, A.; Vella, F. Diagnostic Test for Models Based on Individual Data: A Survey. J. Appl. Econom. 1989, 4, 29-59. [CrossRef]

36. Qin, D.; Liu, Y. Modelling Scale Effect in Cross-Section Data: The Case of Hedonic Price Regression. Available online: http:/ / ssrn.com/abstract=2566709 (accessed on 18 February 2015).

37. Rupert, P.; Zanella, G. Revisiting Wage, Earnings, and Hours Profiles. J. Monet. Econ. 2015, 72, 114-130. [CrossRef]

38. Merkle, E.C.; Fan, J.; Zeileis, A. Testing for Measurement Invariance with Respect to an Ordinal Variable. Psychometrika 2013, 79, 1-16. [CrossRef] [PubMed]

39. Perron, P.; Yamamoto, Y. Using OLS to Estimate and Test for Structural Changes in Models with Endogenous Regressors. J. Appl. Econom. 2013, 30, 119-144. [CrossRef]

40. Angrist, J.D.; Krueger, A.B. Empirical Strategies in Labour Economics. In Handbook of Labor Economics; Ashenfelter, O., Card, D., Eds.; North-Holland: New York, NY, USA, 1999; Volume 3, pp. 1278-1366.

41. Blundell, R.; Bozio, A.; Laroque, G. Extensive and Intensive Margins of Labour Supply: Work and Working Hours in the US, the UK and France. Fisc. Stud. 2013, 34, 1-29. [CrossRef]

42. Eika, L.; Mogstad, M.; Zafar, B. Educational Assortative Mating and Household Income Inequality; National Bureau of Economic Research: Cambridge, MA, USA, 2014.

43. Hendry, D.F. The Methodology of Empirical Econometric Modeling: Applied Econometrics Through the Looking-Glass. In Palgrave Handbook of Econometrics; Mills, T.C., Patterson, K.D., Eds.; Palgrave MacMillan: London, UK, 2009; Volume 2, pp. 3-67.

44. Hendry, D.F. Dynamic Econometrics; Oxford University Press: Oxford, UK, 1995. 
45. Dickens, W.T.; Lang, K. Labor Market Segmentation Theory: Reconsidering the Evidence. In Labor Economics: Problems in Analyzing Labor Markets; Darity, W., Ed.; Kluwer Academic Publishers: Boston, MA, USA, 1993; Part 2; pp. 141-180.

46. Leontaridi, M. Segmented Labour Markets: Theory and Evidence. J. Econ. Surv. 1998, 12, 103-109. [CrossRef]

47. Welch, F. Growth in Women's Relative Wages and in Inequality among Men: One Phenomenon or Two? Am. Econ. Rev. 2000, 90, 444-449. [CrossRef]

48. Bertrand, M.; Kamenica, E.; Pan, J. Gender Identity and Relative Income within Households. Q. J. Econ. 2015, 130, 571-614. [CrossRef]

49. Swamy, P.A.V.B.; Tavlas, G.S.; Hall, S.G. On the Interpretation of Instrumental Variables in the Presence of Specification Errors. Econometrics 2015, 3, 55-64. [CrossRef]

50. Angrist, J.D.; Pischke, J.S. The Credibility Revolution in Empirical Economics: How Better Research Design is Taking the Con out of Econometrics. J. Econ. Perspect. 2010, 24, 3-30. [CrossRef]

51. Kopf, J.; Augustin, T.; Strobl, C. The Potential of Model-based Recursive Partitioning in the Social Sciences-Revisiting Ockham's Razor. In Contemporary Issues in Exploratory Data Mining; McArdle, J.J., Ritschard, G., Eds.; Routledge: New York, NY, USA; London, UK, 2013; pp. 75-95.

52. Little, R.J.A.; Vartivarian, S. Does Weighting for Nonresponse Increase the Variance of Survey Means? Surv. Methodol. 2005, 31, 161-168.

(C) 2015 by the authors; licensee MDPI, Basel, Switzerland. This article is an open access article distributed under the terms and conditions of the Creative Commons by Attribution (CC-BY) license (http:/ / creativecommons.org/licenses/by/4.0/). 